\title{
A Review of Plant-Based Therapies for the Treatment of Urinary Tract Infections in Traditional Southern African Medicine
}

\author{
Ian Cock $\mathbb{D}^{1,2}$ Nothando Mavuso, ${ }^{3}$ and Sandy Van Vuuren ${ }^{3}{ }^{3}$ \\ ${ }^{1}$ School of Environment and Science, Griffith University, Brisbane 4111, Australia \\ ${ }^{2}$ Environmental Futures Research Institute, Griffith University, Brisbane, Australia \\ ${ }^{3}$ Department of Pharmacy and Pharmacology, Faculty of Health Sciences, University of the Witwatersrand, Johannesburg, \\ Gauteng 2193, South Africa \\ Correspondence should be addressed to Sandy Van Vuuren; sandy.vanvuuren@wits.ac.za
}

Received 30 April 2021; Accepted 9 July 2021; Published 30 July 2021

Academic Editor: Olufunmiso Olusola Olajuyigbe

Copyright (C) 2021 Ian Cock et al. This is an open access article distributed under the Creative Commons Attribution License, which permits unrestricted use, distribution, and reproduction in any medium, provided the original work is properly cited.

\begin{abstract}
Urinary tract infections (UTIs) are amongst the most common bacterial infections globally, with 11\% of the world's population contracting at least one infection annually. Several South African plants are used in traditional healing systems to treat UTIs, yet the therapeutic potential of these plants against bacteria that cause UTI remains poorly explored. This study documents southern African plant species used traditionally to treat UTIs. An extensive literature review was undertaken to document the southern African plant species that are used in traditional South African medicine to treat UTIs, thereby highlighting gaps in the current research that require further study. One hundred and fifty-three southern African plant species that are used to treat UTIs were identified. Eighty-five southern African plants were identified as having noteworthy inhibitory activity against the major UTIcausing bacteria. Few of those studies screened against all of the bacterial causes of UTIs, and none of those studies examined the mechanism of action of the plant preparations. Furthermore, many of those studies did not test the toxicity of the plant extracts, so an evaluation of the safety for therapeutic usage was lacking. Substantial further research is to determine their potential for therapeutic use.
\end{abstract}

\section{Introduction}

Urinary tract infections (UTIs) are amongst the most common human infections globally. Indeed, it has been estimated that nearly 800 million people (equating to approximately $11 \%$ of the global population) develop at least one UTI in any given year $[1,2]$. They are substantially more common in women than in men, with the prevalence in women estimated to be approximately five times higher than in males [3]. Indeed, it is expected that more than half of female population of the world will contract at least one UTI in their lifetime, with a substantial proportion experiencing recurrent infections [1]. With the exception of a spike in UTI occurrence in women aged 14-24 years old, the prevalence of UTIs generally increases with age, with the highest incidence in women over 65 years of age [4]. The difference in rates of UTIs between men and women is related to anatomical differences between the genders. As the urethra is located closer to the anus and is shorter in women than in men, women are substantially more susceptible to infections by uropathogens [5]. Additionally, individual health status affects the incidence of UTIs. For example, immunocompromised individuals and sufferers of chronic uncontrolled diabetes mellitus have substantially increased incidences of UTIs as their weakened immune systems are unable to effectively combat infections [3].

Lifestyle and environmental factors also contribute to the prevalence of UTIs. Older adults often accumulate multiple medical conditions, and their treatment and management regimens may increase the risks of contracting UTIs. In particular, catheterisation substantially increases the incidence of UTIs, especially by Gram-negative bacterial pathogens [1]. Indeed, healthcare-associated UTIs have been estimated to account for approximately $10 \%$ of UTI cases, 
with $75 \%$ of these being reported in female patients $[6,7]$. Additionally, prolonged antibiotic usage to treat other medical conditions weakens the immune response, thereby increasing the susceptibility to UTIs. In younger women, increased sexual activity between the ages of 18 to 39 years of age increases both the incidence of UTIs and the frequency of recurrence [4]. Any region of the urinary tract may become infected, including the kidneys, bladder, urethra, and ureter [8]. When the UTIs occur in the lower regions of the urinary tract, the infection is known as a bladder infection (cystitis). Infections in the upper urinary tract (pyelonephritis) are commonly referred to as kidney infections.

\subsection{Types of Urinary Tract Infections. Urinary tract infections} are classified as either complicated or uncomplicated. Complicated infections occur in people with underlying conditions or abnormalities in any part of the genitourinary tract, making the infection more serious and more challenging to treat than uncomplicated infections. In contrast, uncomplicated UTIs are classified as infections occurring in the absence of comorbidities or other anatomical urinary tract and renal abnormalities [9]. The incidence of complicated UTIs is substantially lower than that of uncomplicated UTIs, which occur in otherwise healthy people with normal genitourinary tract anatomy [10]. However, uncomplicated infections are generally easier to manage, and treatment with a short course of antibiotics is usually effective. Urinary tract infections in children and males are generally categorised as uncomplicated infections due to their low probability of comorbidities [8]. Notably, complicated UTI-causative pathogens are linked to increased rates of antimicrobial resistance. Therefore, the development of effective therapies to treat these conditions is vital, not only to decrease the effects of these infections, but also to slow the development of further antibiotic-resistant bacterial strains.

1.2. Causes of Urinary Tract Infections. Interestingly, there can be notable differences between the infectious agents responsible for uncomplicated and complicated UTIs. The vast majority of these pathogens are normal components of the gastrointestinal or vaginal microflora, thereby increasing the chances that they cause UTIs. For both classes of UTI, uropathogenic Escherichia coli are the leading infective agent, accounting for approximately 75 and 65\% for uncomplicated and complicated UTIs, respectively [1]. Klebsiella pneumoniae accounts for a further $6 \%$ and $8 \%$ of uncomplicated and complicated UTIs. The bacterium Staphylococcus saprophyticus causes about $6 \%$ of uncomplicated UTIs yet does not significantly contribute to complicated UTIs. In contrast, Enterococcus spp. contribute substantially to complicated UTI cases $(\sim 11 \%)$, yet contribute less to uncomplicated UTIs $(\sim 6 \%)$. Other bacteria also contribute significantly, albeit with substantially lower rate, to the incidence of UTIs. In particular, Proteus spp. (particularly Proteus mirabilis) and Pseudomonas aeruginosa each cause approximately $2 \%$ of both uncomplicated and complicated cases of UTIs. Other pathogens may occasionally also cause UTIs. For example, Staphylococcus aureus induces a low number of cases of UTIs, although these are generally considered a special case as they are usually secondary to blood $S$. aureus infections. UTIs can also be caused by fungal and viral pathogens, albeit with a substantially lower prevalence than reported for bacterial UTIs. In this review, we focus on the major bacterial causes of UTIs. Therefore, whilst numerous studies have screened traditional medicines for the ability to inhibit $S$. aureus, those studies generally focussed on other diseases (e.g., skin disorders), and we have not listed those studies herein due to the minor role of this bacterium in inducing UTIs. Likewise, Candida albicans infections are a common cause of urethra infections and are thus commonly classed as urethritis rather than a UTI. Therefore, we do not include studies examining the effects of southern African plants to inhibit C. albicans growth in this review. Numerous other studies have examined the effects of southern African plants against C. albicans, and the reader is directed to those studies [11-13]. Notably, those studies generally screened against C. albicans for reasons not associated with UTIs.

The pathogens that cause UTIs usually enter the urinary tract via the urethra. Bacteria are transferred to the urethra from the bowel. When they colonise the bladder, they attach to the bladder wall and form a biofilm, which helps the pathogens to evade the host's immune response [14]. Improper urogenital area hygiene, sexual intercourse, and exposure to unfavourable hygiene products (e.g., scented and chemical filled feminine products and contraceptives) may aid in the introduction of pathogens to the urinary tract and create suitable growth conditions for infections to develop [10]. Other risk factors for contracting an uncomplicated UTI include sexual intercourse with a new sexual partner, use of contraceptives, and a history of previous recurrent UTIs. Risk factors for complicated UTIs are underlying diseases, use of catheters, abnormal genitourinary anatomy and physiology, hospitalisation, and exposure to antibiotics [10].

1.3. Symptoms of Urinary Tract Infections. Urinary tract infections may present in several ways including increased and persistent urgency to urinate, painful burning sensations associated with urination, increased frequency of urination, lower volumes for each urinary event, and cloudy and foul smelling urine. Pain in the lower abdomen, back, and pelvic area is also a relatively common symptom of UTIs, especially in women [8]. Occasionally, UTIs may result in blood in the urine, which may present as red-, pink-, or cola-coloured urine. Infection in the kidney may present with symptoms including nausea and vomiting, fever, and upper back pain (most commonly on a single side) [10]. Many of these signs and symptoms are generic, and UTIs are frequently overlooked or misdiagnosed as other conditions, particularly in older people.

1.4. Current Treatments. In most cases, UTIs are relatively easy to treat with a course of broad-spectrum antibiotics, although fluoroquinolones (including ciprofloxacin) are 
generally avoided as the side effects are often regarded as outweighing the benefits. The most common treatments include trimethoprim/sulfamethoxazole, fosfomycin, nitrofurantoin, cephalexin, and ceftriaxone. However, due to overuse and misuse of commonly used clinical antibiotics, the emergence of antibiotic-resistant pathogens is increasingly common, resulting in the failure of the main antibiotic chemotherapy options [15]. Antibiotic resistance has been a driving force of new drug development initiatives, and implementation of alternative treatment identification and new antibiotic therapies are urgently required.

The development of antibiotic-resistant bacteria is increasingly resulting in antibiotic therapy failures, and chronic UTIs are becoming more frequent [1]. Additionally, the relatively high rate of UTI recurrence poses a challenge to the effective treatment of these infections [16]. Indeed, that study estimated that approximately $24 \%$ of people contracting a UTI will develop a recurrent infection within six months of the original infection. Of further concern, approximately $5 \%$ of people who develop a UTI will experience more than three recurrences per year [17].

Foxman and Buxton [18] suggest that empirical treatments of UTIs should be reconsidered due to the following reasons:

(i) The frequency of antibiotic-resistant E. coli strains, many of which have resistance to multiple antibiotics including fluoroquinolones [15], is increasing. The increasing incidence of extended spectrum $\beta$-lactamase (ESBL) UTI pathogens that are resistant to the commonly used $\beta$-lactam class of antibiotics is particularly concerning $[19,20]$.

(ii) Even relatively short courses of currently used antibiotic therapies may significantly affect the gut microflora, resulting in other health issues developing [21]. These therapies may also disrupt the urogenital microbiome, resulting in other unforeseen issues. Thus, the benefits of empirical antibiotic therapy may not outweigh the risks [22, 23]. New and innovative strategies to prevent UTI recurrences and alternative therapies for their treatment are considered a high priority [18].

\footnotetext{
1.5. The Use of Medicinal Plants in Urinary Tract Infection Treatment. The launch and development of the WHO Traditional Medicine Strategy 2014-2023 aimed to support the development and implementation of proactive policies and action plans to improve the role traditional medicine plays in population health [24]. The strategy focuses on developing new health systems (including the use of complementary and traditional medicinal products) as a high priority. A re-examination of traditional medicines is an attractive option for the development of new therapies to treat pathogenic infections as plant-derived medicines have often been used for hundreds (in some cases, thousands) of years. Furthermore, the traditional use by some cultures has been relatively well documented. Asian, Middle Eastern, and African traditional systems are perhaps the most extensively
}

documented, although many of the therapies are yet to be extensively studied and verified, and substantially more work is needed in this field.

It is estimated that approximately 700,000 tons of plant materials are used each year in South Africa to produce herbal remedies worth 1.2 to 2.5 billion South African Rands annually [25-28]. Not only are these products widely used in South Africa by practitioners of traditional medicine, but they are also becoming increasingly popular as complementary and alternative medicines in combination with allopathic pharmaceuticals. Indeed, some plant products (e.g., Harpagophytum procumbens (Burch.) DC. Ex Meisn., commonly known as devil's claw extracts) are commonly sold at pharmacies globally, and it is no longer necessary to visit a traditional Muthi market to obtain products developed from them. However, a substantial portion of traditional plant use in South Africa does use plant materials obtained and prepared following traditional methods. Depending on the plant species used, a variety of different parts including roots, flowers, leaves, bulbs, and stems may be used medicinally, and the individual parts may have substantially different properties and uses [29]. Traditional beliefs have a deep influence within the majority of the ethnic cultures in South Africa and are particularly prevalent in rural communities [30]. Even in urban communities, a large portion of the South African population is reliant on traditional medicine as their primary mode of healthcare [31]. Indeed, that study postulated that the demand for traditional medicines in South Africa will increase in future years due to stress associated with urban lifestyles.

Despite their widespread use, there is a relative lack of information on the proper use and preservation of plant medicines. Medicinal plants are considered (often erroneously) to have fewer adverse effects [32] and are often more accessible and affordable than Western/allopathic medications [33]. A substantial number of South Africans (especially rural populations) are dependent on self-medication with plant-based medicines, and the involvement of the community in managing the use and preservation of plant species may result in successful strategies for sustainable use [34]. South African ethnobotanical literature has been relatively well recorded, although the medicinal properties of many species used traditionally are yet to be rigorously verified. There has been a substantial increase in studies screening and validating the use of South African traditional medicines in recent years, highlighting the potential of several species [35]. Of the therapeutic properties examined, the antibacterial activity of South African plants has received the most attention, although many species remain relatively neglected. Numerous plants have been reported to have antimicrobial activity, with a substantial recent increase in interest in this field. However, very few of those studies have specifically focussed on UTIs. Instead, screening against bacterial pathogens that cause gastrointestinal diseases $[36,37]$, skin disease $[38,39]$, or autoimmune diseases $[40,41]$ have received far greater attention. Notably, many of the same bacterial species screened in the other studies are also amongst the pathogenic causes of UTIs. Whilst the focus of those studies is not UTIs, they are included in this 
study as they were screened against the same bacterial species.

\section{Materials and Methods}

This study aimed to record and document the southern African medicinal plants that are used traditionally to treat UTIs. A variety of ethnobotanical books [42-46], as well as multiple peer reviewed journal articles, were consulted to compile this list. The online resources Google Scholar, PubMed, Scopus, and ScienceDirect were used to identify and access original scientific research studies. The following terms were used as filters and were searched for both alone and as combination: "Southern Africa," "South African," "Lesotho," "Swaziland," "Namibia," "Botswana," "Zimbabwe," "Zambia," "Mozambique," "traditional medicinal plant," "ethnobotany," "urinary tract infection," "UTI," "bladder," and "uropathogens." The initial search aimed to document all of the plant species used in southern Africa to treat UTIs. Our study was nonbiased and did not favour the traditional knowledge of one ethnic group over others. Despite this, substantially more information was available about Zulu traditional medicine due to the prevalence of reports on that topic in the available literature. Whilst most of these species are native South African plants, introduced species were not excluded, where they had been incorporated into the traditional medicine systems of at least one South African ethnic group. Following the initial literature review, a further review was undertaken to identify the species that have been screened for their ability to inhibit one or more of the bacterial pathogens that cause UTIs.

2.1. Eligibility Criteria. Ethnobotanical books and peer reviewed journal articles were searched using the specific key words noted above. Published studies were identified and their abstracts were read to establish their relevance to this study. The full content of publications that were deemed relevant were then examined thoroughly to ensure that the eligibility criteria were met.

2.2. Inclusion Criteria. The following inclusion criteria for eligibility of the study were considered:

(i) Publications written in English and prior to April 2021 were used in this review.

(ii) Our study was nonbiased and without any taxonomic preference.

(iii) For the ethnobotanical survey (Table 1), only plant species that are recorded to treat UTIs are included. Any plants recorded to treat individual nonspecific symptoms were excluded unless it could be determined that they were specifically used to treat UTIs.

(iv) For the biological activity studies presented in Table 2, only studies that screened against the major bacterial causes of UTIs were included, irrespective of whether the focus of the study was UTIs or the bacteria tested were selected because of their association with a different disease. (v) Only studies screening against the common causes of UTIs were evaluated in this review, irrespective of their focus. For example, studies that screened southern African plants against E. coli were included in this study, even if their focus was on gastrointestinal diseases rather than UTIs.

(vi) Ethnobotanical studies on the flora of southern African region included South Africa and those countries immediately surrounding it.

2.3. Exclusion Criteria. The following criteria were used to exclude some studies:

(i) Where name changes and families of plant species were encountered, particularly in older publications, websites such as The Plant List (http://www. theplantlist.org/) and South African National Biodiversity Institute (SANBI) (http://www.sanbi.org) were used to confirm species identification.

(ii) Plant species that were recorded to treat generic symptoms of UTIs that are common to other illnesses, without specifically stating their use in treating UTIs, were excluded from this study.

(iii) Studies that screened against bacteria that only cause UTIs secondary to other diseases were excluded. Therefore, studies screening South African plants for S. aureus, which only causes UTIs secondary to blood S. aureus infections, were not included in this study.

(iv) Only screening studies that tested against bacterial pathogens were included in this study. Publications that screened South African plants for fungi, viruses, or protozoa were excluded.

(v) The use of introduced plant species were excluded from this study unless they are extensively used as part of southern African traditional medicine of at least one South African ethnic group.

2.4. Data Collection. A thorough literature search for publications on southern African medicinal plants used traditionally to treat UTIs was undertaken and is summarised in this study. Additionally, in vivo and in vitro biological screening of South African medicinal plants for bacterial pathogens that cause UTIs are summarised, regardless of the origin of the study. The following data was collected for each species:

(i) Species name, family name, and common name for each species recorded in the individual publications were collected

(ii) Common names and the names used by different ethnic groups (where appropriate) were collected from individual publications and from the SANBI red list website

(iii) The plant part used, method of preparation, and mode of administration were recorded where that information was provided 
TABLE 1: Southern African plants traditionally used to treat urinary tract infections.

\begin{tabular}{|c|c|c|c|c|c|}
\hline Plant species & Family & Common name & $\begin{array}{c}\text { Part of plant } \\
\text { used }\end{array}$ & Uses & References \\
\hline $\begin{array}{l}\text { Acacia sieberiana var. woodii } \\
\text { (Burtt Davy) Keay \& Brenan }\end{array}$ & Leguminosae & $\begin{array}{l}\text { Paperbark thorn (Eng); } \\
\text { papierbasdoring (Afr) }\end{array}$ & $\begin{array}{l}\text { Bark and } \\
\text { roots }\end{array}$ & $\begin{array}{l}\text { Urinary tract } \\
\text { ailments }\end{array}$ & {$[46]$} \\
\hline $\begin{array}{l}\text { Acokanthera oppositifolia } \\
\text { (Lam.) Codd }\end{array}$ & Apocynaceae & Inhlungunyembe (Zulu) & Not specified & $\begin{array}{l}\text { Urinary tract } \\
\text { infection }\end{array}$ & {$[43]$} \\
\hline $\begin{array}{l}\text { Afroaster hispida (Thunb.) } \\
\text { J.C.Manning \& Goldblatt }\end{array}$ & Asteraceae & Udlutshana (Zulu) & Not specified & Urinary ailments & {$[47]$} \\
\hline $\begin{array}{l}\text { Agathosma betulina } \\
\text { (P.J.Bergius) Pillans }\end{array}$ & Rutaceae & $\begin{array}{c}\text { Buchu (Eng); boegoe (Afr); bocho } \\
\text { (Sotho) }\end{array}$ & Leaves & $\begin{array}{c}\text { Bladder and } \\
\text { kidney ailments }\end{array}$ & {$[45,48,49]$} \\
\hline $\begin{array}{l}\text { Agathosma capensis (L.) } \\
\text { Dummer }\end{array}$ & Rutaceae & $\begin{array}{l}\text { Spicy buchu (Eng); anysboegoe, } \\
\text { steenbokboegoe (Afr) }\end{array}$ & Leaves & Urinary ailments & {$[50]$} \\
\hline $\begin{array}{l}\text { Agathosma serratifolia } \\
\text { (Curtis) Spreeth }\end{array}$ & Rutaceae & $\begin{array}{l}\text { Langblaarboegoe, kloofboegoe } \\
\text { (Afr); long buchu (Eng) }\end{array}$ & Leaves & $\begin{array}{c}\text { Bladder and } \\
\text { kidney ailments }\end{array}$ & {$[45]$} \\
\hline $\begin{array}{l}\text { Albizia adianthifolia (Schum.) } \\
\text { W.Wight }\end{array}$ & Leguminosae & $\begin{array}{l}\text { Isiyengelele, usolo, } \\
\text { umgadankawu (Zulu) }\end{array}$ & Not specified & $\begin{array}{l}\text { Urinary tract } \\
\text { infection }\end{array}$ & {$[47]$} \\
\hline Aloe ferox Mill. & Xanthorrhoeaceae & $\begin{array}{c}\text { Bitteraalwyn (Afr); bitter aloe } \\
\text { (Eng) }\end{array}$ & $\begin{array}{l}\text { Leaves, roots, } \\
\text { and stems }\end{array}$ & $\begin{array}{l}\text { Kidney and } \\
\text { bladder ailments }\end{array}$ & {$[51]$} \\
\hline Aloe zebrina Baker & Xanthorrhoeaceae & $\begin{array}{c}\text { Sebra-aalwyn (Afr); zebra aloe } \\
\text { (Eng) }\end{array}$ & Leaves & $\begin{array}{l}\text { Urinary and } \\
\text { bladder ailments }\end{array}$ & {$[46]$} \\
\hline $\begin{array}{l}\text { Antiphiona pinnatisecta } \\
\text { (S.Moore) Merxm. }\end{array}$ & Compositae & Unknown & Roots & Bladder ailments & {$[46]$} \\
\hline $\begin{array}{l}\text { Antizoma angustifolia } \\
\text { (Burch.) Miers ex Harv. }\end{array}$ & Menispermaceae & Maagbitterwortel (Afr) & Roots & $\begin{array}{l}\text { Kidney and } \\
\text { bladder ailments }\end{array}$ & {$[52]$} \\
\hline $\begin{array}{l}\text { Aptosimum procumbens } \\
\text { (Lehm.) Burch. ex Steud }\end{array}$ & Scrophulariaceae & Brandbos (Afr) & Leaves & Bladder ailments & {$[42-44]$} \\
\hline Arctopus echinatus L. & Apiaceae & Platdoring $(\mathrm{Afr})$ & Roots & Bladder ailments & {$[42-44,53]$} \\
\hline Artemisia afra Jacq. ex Willd. & Compositae & $\begin{array}{l}\text { Alsem (Afr); African wormwood } \\
\text { (Eng); mhlonyana (Zulu) }\end{array}$ & $\begin{array}{l}\text { Leaves, roots, } \\
\text { and stems }\end{array}$ & $\begin{array}{l}\text { Bladder and } \\
\text { kidney ailments }\end{array}$ & {$[49,51]$} \\
\hline Asparagus africanus Lam. & Asparagaceae & $\begin{array}{c}\text { Bush asparagus, African } \\
\text { asparagus (Eng); katdoring (Afr); } \\
\text { isigobo (Zulu) }\end{array}$ & Not specified & $\begin{array}{l}\text { Bladder and } \\
\text { kidney ailments }\end{array}$ & {$[46]$} \\
\hline $\begin{array}{l}\text { Asparagus asparagoides (L.) } \\
\text { Druce }\end{array}$ & Asparagaceae & Makholela (Sotho) & Roots & $\begin{array}{l}\text { Urinary tract } \\
\text { infection }\end{array}$ & {$[48]$} \\
\hline $\begin{array}{l}\text { Aster bakerianus Burtt Davy } \\
\text { ex C.A.Sm. }\end{array}$ & Compositae & Idlutshane, uhloshana (Zulu) & Leaves & $\begin{array}{l}\text { Urinary tract } \\
\text { infection }\end{array}$ & {$[43]$} \\
\hline $\begin{array}{l}\text { Baccharoides adoensis var. } \\
\text { kotschyana (Sch.Bip. ex } \\
\text { Walp.) }\end{array}$ & Compositae & Innyathelo (Zulu) & $\begin{array}{l}\text { Stems and } \\
\text { leaves }\end{array}$ & $\begin{array}{l}\text { Urinary tract } \\
\text { infection }\end{array}$ & {$[43]$} \\
\hline Ballota africana (L.) Benth. & Lamiaceae & Kattekruid (Afr) & Leaves & $\begin{array}{c}\text { Bladder and } \\
\text { kidney ailments }\end{array}$ & {$[50]$} \\
\hline Berkheya Setifera DC. & Compositae & $\begin{array}{c}\text { Ikhakhasi, umalumvuba (Zulu); } \\
\text { leleme-la-khomo (Sotho) }\end{array}$ & Root & $\begin{array}{l}\text { Urinary and } \\
\text { kidney ailments }\end{array}$ & {$[47,54]$} \\
\hline $\begin{array}{l}\text { Bolusanthus speciosus (Bolus) } \\
\text { Harms }\end{array}$ & Leguminosae & $\begin{array}{l}\text { Umholo (Zulu); tree wisteria } \\
\text { (Eng); vanwykshout (Afr) }\end{array}$ & $\begin{array}{l}\text { Barks, leaves, } \\
\text { and stems }\end{array}$ & Kidney ailments & {$[55]$} \\
\hline Boophone disticha (L.f.) Herb. & Amaryllidaceae & Gifbol (Afr) & Bulb & Bladder ailments & {$[42-44]$} \\
\hline Bowiea volubilis Harv. & Asparagaceae & $\begin{array}{c}\text { Climbing onion (Eng); } \\
\text { knolklimop (Afr); iguleni (Zulu) }\end{array}$ & Bulb & Bladder ailments & {$[43,48]$} \\
\hline Brachylaena discolor DC. & Compositae & Bosvaalbos (Afr); ipahla (Zulu) & Leaves & Urinary ailments & [43] \\
\hline Bulbine abyssinica A.Rich & Xanthorrhoeaceae & Wildekopieva (Afr) & Leaves & Bladder ailments & {$[56,57]$} \\
\hline Bulbine latifolia (L.f.) Spreng. & Xanthorrhoeaceae & Red carrot (Eng); rooiwortel (Afr) & Root & $\begin{array}{l}\text { Bladder and } \\
\text { kidney ailments }\end{array}$ & {$[48,57]$} \\
\hline $\begin{array}{l}\text { Cardiospermum halicacabum } \\
\text { L. }\end{array}$ & Sapindaceae & $\begin{array}{c}\text { Balloon vine (Eng); blaasklimop } \\
\text { (Afr) }\end{array}$ & $\begin{array}{l}\text { Stems and } \\
\text { leaves }\end{array}$ & Bladder ailments & {$[43,46,58]$} \\
\hline Carica papaya L. & Caricaceae & Papaya, pawpaw (Eng) & Not specified & Bladder ailments & {$[42]$} \\
\hline Cenchrus ciliaris L. & Poaceae & $\begin{array}{l}\text { Buffalograss (Eng); bloubuffelgras } \\
\text { (Afr); idungamuzi (Zulu) }\end{array}$ & Roots & $\begin{array}{l}\text { Urinary tract } \\
\text { infection }\end{array}$ & {$[43,59,60]$} \\
\hline Centaurea benedicta (L.) L. & Compositae & Karmedik (Afr) & Not specified & $\begin{array}{c}\text { Urinary and } \\
\text { kidney ailments }\end{array}$ & {$[50]$} \\
\hline Chironia baccifera L. & Gentianaceae & Bitterbos, sarsaparilla (Afr) & Not specified & Urinary ailments & [50] \\
\hline
\end{tabular}


TABle 1: Continued.

\begin{tabular}{|c|c|c|c|c|c|}
\hline Plant species & Family & Common name & $\begin{array}{c}\text { Part of plant } \\
\text { used }\end{array}$ & Uses & References \\
\hline $\begin{array}{l}\text { Chrysanthemoides monilifera } \\
\text { (L.) Norl. }\end{array}$ & Compositae & Bietou, bessiebos (Afr) & Whole plant & $\begin{array}{c}\text { Urinary and } \\
\text { kidney ailments }\end{array}$ & {$[50]$} \\
\hline Cissampelos capensis L.f. & Menispermaceae & $\begin{array}{c}\text { David's root (Eng); gifhondjie, } \\
\text { dawidjieswortel (Afr) }\end{array}$ & $\begin{array}{l}\text { Roots and } \\
\text { leaves }\end{array}$ & Bladder ailments & {$[42-44,46]$} \\
\hline Cleome gynandra L. & Cleomaceae & $\begin{array}{l}\text { African cabbage, spiderwisp } \\
\text { (Eng); snotterbelletjie (Afr) }\end{array}$ & Not specified & Bladder ailments & {$[42]$} \\
\hline Cliffortia odorata L.f. & Rosaceae & $\begin{array}{l}\text { Wildewingerd (Afr); wild vine } \\
\text { (Eng) }\end{array}$ & Leaves & Bladder ailments & {$[48]$} \\
\hline Clivia miniata (Lindl.) Bosse & Amaryllidaceae & $\begin{array}{l}\text { Benediction lily (Eng); boslelie } \\
\text { (Afr); umayime (Zulu) }\end{array}$ & Bulb & Urinary ailments & {$[43]$} \\
\hline Coix lacryma-jobi L. & Poaceae & Job’s tears, adlay (Eng) & Not specified & Bladder ailments & {$[42]$} \\
\hline Combretum kraussii Hochst. & Combretaceae & $\begin{array}{l}\text { Umduba, umdubu omhlophe, } \\
\text { umdubo wamanzi (Zulu) }\end{array}$ & Not specified & $\begin{array}{c}\text { Urinary and } \\
\text { bladder ailments }\end{array}$ & {$[47]$} \\
\hline Commelina africana $\mathrm{L}$. & Commelinaceae & $\begin{array}{c}\text { Idangabane (Zulu); khopo } \\
\text { (Sotho) }\end{array}$ & Root & Bladder ailments & {$[43]$} \\
\hline $\begin{array}{l}\text { Conostomium natalense } \\
\text { (Hochst.) Bremek. }\end{array}$ & Rubiaceae & $\begin{array}{c}\text { Wild pentas (Eng); umbophe, } \\
\text { ungcolosi (Zulu) }\end{array}$ & Not specified & Urinary ailments & {$[61]$} \\
\hline Conyza scabrida DC. & Compositae & Oondbos, bakbos, paddabos (Afr) & Leaves & Bladder infection & {$[51]$} \\
\hline Crinum macowanii Baker & Amaryllidaceae & River fly (Eng); umduze (Zulu) & Bulb & Urinary ailments & {$[43]$} \\
\hline Crinum moorei Hook. f. & Amaryllidaceae & Umduze (Zulu) & Bulb & Urinary ailments & {$[43]$} \\
\hline $\begin{array}{l}\text { Crossyne guttata (L.) D.Müll.- } \\
\text { Doblies \& U.Müll.-Doblies }\end{array}$ & Amaryllidaceae & Gifbol (Afr) & Bulb & Bladder ailments & {$[42-44]$} \\
\hline $\begin{array}{l}\text { Cryptolepis oblongifolia } \\
\text { (Meisn.) Schltr. }\end{array}$ & Apocynaceae & $\begin{array}{c}\text { Bokhoring, melkbos (Afr); } \\
\text { mukangaza (Sotho) }\end{array}$ & Not specified & Bladder ailments & {$[42]$} \\
\hline $\begin{array}{l}\text { Cussonia paniculata Eckl. \& } \\
\text { Zeyh. }\end{array}$ & Araliaceae & Motsetse (Sotho) & Not specified & $\begin{array}{c}\text { Kidney and } \\
\text { bladder ailment }\end{array}$ & {$[54,62]$} \\
\hline $\begin{array}{l}\text { Cyathula achyranthoides } \\
\text { (Kunth) Moq. }\end{array}$ & Amaranthaceae & Unknown & Not specified & Bladder ailments & {$[63]$} \\
\hline Cynodon dactylon (L.) Pers. & Poaceae & $\begin{array}{c}\text { Dog's tooth (Eng); krookgras } \\
\text { (Afr) }\end{array}$ & Rhizome & Urinary ailments & {$[46]$} \\
\hline Datura stramonium $\mathrm{L}$. & Solanaceae & $\begin{array}{c}\text { Thornapple, jimsonweed, devil's } \\
\text { snare (Eng) }\end{array}$ & Leaves & Bladder ailments & {$[42]$} \\
\hline Dicoma capensis Less. & Compositae & Karmedik, wilde karmedik (Afr) & Leaves & $\begin{array}{l}\text { Bladder and } \\
\text { kidney ailments }\end{array}$ & {$[44,45,56,57]$} \\
\hline Diosma oppositifolia L. & Rutaceae & Buchu, Bitter buchu (Eng) & Leaves & $\begin{array}{c}\text { Bladder and } \\
\text { kidney ailments }\end{array}$ & {$[48]$} \\
\hline Diosma prama I.Williams & Rutaceae & Steenbokkboegoe (Afr) & Not specified & $\begin{array}{l}\text { Urinary and } \\
\text { kidney ailments }\end{array}$ & {$[50]$} \\
\hline $\begin{array}{l}\text { Diospyros mespiliformis } \\
\text { Hochst. ex A.DC }\end{array}$ & Ebenaceae & $\begin{array}{l}\text { Ikhambi lesduli, umazambezi } \\
\text { (Zulu) }\end{array}$ & Not specified & Urinary ailments & {$[47]$} \\
\hline Dipcadi gracillimum Baker & Asparagaceae & Oumasegroottoon (Afr) & Not specified & Bladder ailments & {$[63]$} \\
\hline Dipcadi viride (L.) Moench & Asparagaceae & $\begin{array}{l}\text { Ugibizisila, uguleni, } \\
\text { umakhweyana (Zulu) }\end{array}$ & Not specified & $\begin{array}{l}\text { Urinary tract } \\
\text { infection }\end{array}$ & {$[47]$} \\
\hline Dipcadi gracillimum Baker & Asparagaceae & Oumasegroottoon (Afr) & Not specified & Urinary ailments & {$[64]$} \\
\hline Dodonaea viscosa (L.) Jacq. & Sapindaceae & $\begin{array}{l}\text { Basterolen, sandolien, ysterbos } \\
\text { (Afr); sand olive (Eng) }\end{array}$ & Leaves & $\begin{array}{l}\text { Bladder and } \\
\text { kidney ailments }\end{array}$ & {$[5,50,51]$} \\
\hline Drimia elata Jacq. & Asparagaceae & $\begin{array}{c}\text { Satin squill (Eng); brandui, } \\
\text { jeukbol (Afr); umqumbu (Zulu) }\end{array}$ & Not specified & Urinary ailments & {$[44]$} \\
\hline $\begin{array}{l}\text { Dysphania ambrosioides (L.) } \\
\text { Mosyakin \& Clemants }\end{array}$ & Amaranthaceae & $\begin{array}{l}\text { Ikhambi leslumo, } \\
\text { uzansikwesibaya (Zulu) }\end{array}$ & Not specified & Urinary ailments & {$[47]$} \\
\hline $\begin{array}{l}\text { Elytropappus rhinocerotis } \\
\text { (L.f.) Less. }\end{array}$ & Asteraceae & Renosterbos (Afr) & Leaves & $\begin{array}{c}\text { Bladder and } \\
\text { kidney disorders }\end{array}$ & {$[49]$} \\
\hline Elymus repens (L.) Gould & Poaceae & Couch grass (Eng) & Not specified & Bladder ailments & {$[42]$} \\
\hline $\begin{array}{l}\text { Empleurum unicapsulare } \\
\text { (L.f.) Skeels }\end{array}$ & Rutaceae & $\begin{array}{c}\text { Bergboegoe, langblaarboegoe } \\
\text { (Afr) }\end{array}$ & Whole plant & $\begin{array}{l}\text { Urinary and } \\
\text { kidney ailments }\end{array}$ & {$[50]$} \\
\hline Eriocephalus punctulatus DC. & Compositae & Kapokbos (Afr) & Whole plant & $\begin{array}{c}\text { Urinary and } \\
\text { kidney ailments }\end{array}$ & {$[50]$} \\
\hline Eriosema distinctum N.E.Br. & Leguminosae & Ubangalala omkhulu (Zulu) & Roots & Urinary ailments & {$[43]$} \\
\hline
\end{tabular}


TABle 1: Continued.

\begin{tabular}{|c|c|c|c|c|c|}
\hline Plant species & Family & Common name & $\begin{array}{l}\text { Part of plant } \\
\text { used }\end{array}$ & Uses & References \\
\hline Erythrina caffra Thunb. & Leguminosae & $\begin{array}{l}\text { Coral tree (Eng); kaffirboom } \\
\text { (Afr); umsinsi (Zulu) }\end{array}$ & Leaves & Urinary ailments & {$[43]$} \\
\hline Erythrina lysistemon Hutch. & Leguminosae & Umsinsi (Zulu) & Leaves & Bladder ailments & {$[47]$} \\
\hline Euclea natalensis A.DC. & Ebenaceae & IsiZimane, umshekisane (Zulu) & Bark & $\begin{array}{l}\text { Urinary tract } \\
\text { infection }\end{array}$ & {$[47,65]$} \\
\hline Euclea undulata Thunb. & Ebenaceae & $\begin{array}{c}\text { Ghwarrie, ghwarrieboom, } \\
\text { ghwarriebos (Afr) }\end{array}$ & Whole plant & $\begin{array}{l}\text { Urinary and } \\
\text { kidney ailments }\end{array}$ & {$[43,50]$} \\
\hline $\begin{array}{l}\text { Eucomis autumnalis (Mill.) } \\
\text { Chitt }\end{array}$ & Asparagaceae & Mathethebane (Sotho) & Tubular roots & Urinary ailments & {$[58]$} \\
\hline Euphorbia milii Des Moul. & Euphorbiaceae & Crown of thorns (Eng) & Not specified & Bladder ailments & {$[64,66]$} \\
\hline Euphorbia tithymaloides L. & Euphorbiaceae & Redbird flower (Eng) & Not specified & Bladder ailments & {$[64,66]$} \\
\hline $\begin{array}{l}\text { Exomis microphylla (Thunb.) } \\
\text { Aellen }\end{array}$ & Amaranthaceae & Hondepisbos, hondebossie (Afr) & Whole plant & Urinary ailments & {$[50]$} \\
\hline $\begin{array}{l}\text { Faidherbia albida (Delile) } \\
\text { A.Chev. }\end{array}$ & Leguminosae & Anatree (Eng); anaboom (Afr) & Bark & Bladder ailments & {$[46]$} \\
\hline Foeniculum vulgare Mill. & Apiaceae & $\begin{array}{l}\text { Vinkel, makuinkel, soetvinkel } \\
\text { (Afr) }\end{array}$ & Whole plant & Urinary ailments & {$[50]$} \\
\hline Galenia africana $\mathrm{L}$. & Aizoaceae & Kraalbos (Afr) & Leaves & Bladder ailments & {$[42-44]$} \\
\hline Galium tomentosum Thunb. & Rubiaceae & $\begin{array}{c}\text { Red storm (Eng); rooistorm, } \\
\text { doodlief (Afr) }\end{array}$ & Root & Bladder ailments & {$[48,56]$} \\
\hline Geranium incanum Burm.f. & Geraniaceae & $\begin{array}{c}\text { Carpet geranium (Eng); horlosie, } \\
\text { bergtee, vrouetee (Afr); tlako } \\
\text { (Sotho) }\end{array}$ & Not specified & Bladder ailments & {$[56,64]$} \\
\hline Grewia caffra Meisn. & Malvaceae & Upata, iphatha (Zulu) & Roots, bark & Bladder ailment & {$[67]$} \\
\hline Grewia occidentalis L. & Malvaceae & $\begin{array}{l}\text { Cross berry (Eng); iklolo, } \\
\text { imahlehle (Zulu) }\end{array}$ & Roots & Bladder ailments & {$[43]$} \\
\hline Grewia robusta Burch. & Malvaceae & Bokbos (Afr) & Whole plant & Urinary ailments & {$[50]$} \\
\hline Gunnera perpensa L. & Gunneraceae & Ugobho, izibu (Zulu) & Not specified & Bladder ailments & {$[47]$} \\
\hline $\begin{array}{l}\text { Helichrysum crispum (L.) } \\
\text { D. Don }\end{array}$ & Compositae & Kooigoed (Afr) & Leaf & $\begin{array}{c}\text { Bladder and } \\
\text { kidney ailments }\end{array}$ & {$[49]$} \\
\hline $\begin{array}{l}\text { Helichrysum odoratissimum } \\
\text { (L.) Sweet }\end{array}$ & Compositae & $\begin{array}{c}\text { Phefo (Sotho); kooigoed, kooibos } \\
\text { (Afr) }\end{array}$ & $\begin{array}{l}\text { Leaves, roots, } \\
\text { and stems }\end{array}$ & Bladder ailments & {$[50,56]$} \\
\hline $\begin{array}{l}\text { Helichrysum patulum (L.) } \\
\text { D.Don }\end{array}$ & Compositae & $\begin{array}{c}\text { Honey everlasting (Eng); } \\
\text { kooigoed (Afr); impepho (Zulu) }\end{array}$ & Not specified & Bladder ailments & {$[42]$} \\
\hline Hibiscus pusillus Thunb. & Malvaceae & Blaasbossie (Afr) & Whole plant & Urinary ailments & {$[50]$} \\
\hline Hibiscus mastersianus Hiern & Malvaceae & Monarch rosemallow (Eng) & $\begin{array}{l}\text { Stems and } \\
\text { Leaves }\end{array}$ & Urinary ailments & {$[46]$} \\
\hline Hibiscus pedunculatus L.f. & Malvaceae & $\begin{array}{c}\text { Pink mallow (Eng); indola } \\
\text { ebomvu (Zulu) }\end{array}$ & Leaves & Urinary ailments & {$[43]$} \\
\hline Hoslundia opposita Vahl & Lamiaceae & $\begin{array}{l}\text { Bird gooseberry (Eng); } \\
\text { uyaweyawe (Zulu) }\end{array}$ & Not specified & Urinary ailments & {$[46]$} \\
\hline $\begin{array}{l}\text { Hypoxis hemerocallidea } \\
\text { Fisch., C.A.Mey. \& Avé-Lall. }\end{array}$ & Hypoxidaceae & Inkanfe (Zulu); yellow star (Eng) & Not specified & Bladder ailments & {$[47,50]$} \\
\hline Hypoxis rigidula Baker & Hypoxidaceae & $\begin{array}{l}\text { Ilabatheka, inkomfe, umhungulo } \\
\text { (Zulu); African potato (Eng) }\end{array}$ & Not specified & Bladder ailments & {$[47,50]$} \\
\hline Indigofera cassioides DC. & Leguminosae & Unknown & Not specified & Bladder ailments & {$[42]$} \\
\hline Ipomoea pes-caprae (L.) R.Br. & Convolvulaceae & $\begin{array}{l}\text { Beach morning glory, goat's foot } \\
\text { (Eng); strandpatat (Afr) }\end{array}$ & Not specified & Bladder ailments & {$[42]$} \\
\hline $\begin{array}{l}\text { Jasminum abyssinicum } \\
\text { Hochst. ex DC. }\end{array}$ & Oleaceae & Mthundangazi & Roots & Bladder ailments & {$[68]$} \\
\hline Kedrostis capensis A. Meeuse & Cucurbitaceae & Sesepa sa linoha (Sotho) & $\begin{array}{l}\text { Tubular roots } \\
\text { and leaves }\end{array}$ & $\begin{array}{l}\text { Urinary tract } \\
\text { infection }\end{array}$ & {$[69]$} \\
\hline $\begin{array}{l}\text { Ledebouria marginata (Baker) } \\
\text { Jessop }\end{array}$ & Asparagaceae & Bokhoe (Sotho) & Root bulb & $\begin{array}{l}\text { Urinary tract } \\
\text { infection }\end{array}$ & {$[70]$} \\
\hline Leonotis leonurus (L.) R.Br. & Lamiaceae & Klip dagga, wild dagga (Afr) & $\begin{array}{l}\text { Stems with } \\
\text { leaves and } \\
\text { flowers }\end{array}$ & $\begin{array}{l}\text { Bladder and } \\
\text { kidney disorders, }\end{array}$ & {$[49]$} \\
\hline $\begin{array}{l}\text { Lessertia frutescens (L.) } \\
\text { Goldblatt \& J.C.Manning }\end{array}$ & Leguminosae & Kalkoenblom, keurtjie (Afr) & Leaves & $\begin{array}{l}\text { Kidney and } \\
\text { urinary ailments }\end{array}$ & {$[50,56]$} \\
\hline
\end{tabular}


TABle 1: Continued.

\begin{tabular}{|c|c|c|c|c|c|}
\hline Plant species & Family & Common name & $\begin{array}{l}\text { Part of plant } \\
\text { used }\end{array}$ & Uses & References \\
\hline Matricaria chamomilla L. & Compositae & Chamomile (Eng) & Not specified & Bladder ailments & {$[42]$} \\
\hline Melianthus pectinatus Harv. & Melianthaceae & Kriekiebos, lidjiebos (Afr) & Root & $\begin{array}{l}\text { Urinary tract } \\
\text { infection }\end{array}$ & {$[56]$} \\
\hline Mentha longifolia (L.) L. & Lamiaceae & $\begin{array}{l}\text { Wild mint (Eng); ufuthana } \\
\text { lomhlanga (Zulu) }\end{array}$ & Leaves & $\begin{array}{l}\text { Bladder and } \\
\text { kidney ailments }\end{array}$ & {$[49,52,68]$} \\
\hline $\begin{array}{l}\text { Merwilla plumbea (Lindl.) } \\
\text { Speta }\end{array}$ & Asparagaceae & $\begin{array}{c}\text { Inguduza, untabosizi, untangana } \\
\text { zibomvana (Zulu) }\end{array}$ & Not specified & Bladder ailments & {$[47,50]$} \\
\hline $\begin{array}{l}\text { Mesembryanthemum } \\
\text { cordifolium L.f. }\end{array}$ & Aizoaceae & Ibohlololo (Zulu) & Leaves & Bladder ailment & {$[44,47,53]$} \\
\hline $\begin{array}{l}\text { Mesembryanthemum } \\
\text { crystallinum L. }\end{array}$ & Aizoaceae & $\begin{array}{l}\text { Common ice plant, crystalline ice } \\
\text { plant (Eng); soutslaai, } \\
\text { volstruisslaai (Afr) }\end{array}$ & Not specified & Bladder ailments & {$[42]$} \\
\hline Mikania capensis DC. & Compositae & Umdlonzo, umhlozo (Zulu) & Leaves & Urinary ailments & {$[42,43]$} \\
\hline Millettia oblata Dunn & Leguminosae & Unknown & Roots & Bladder ailments & [42] \\
\hline $\begin{array}{l}\text { Notobubon galbanum (L.) } \\
\text { Magee }\end{array}$ & Apiaceae & $\begin{array}{c}\text { Blister bush (Eng); bergseldery } \\
\text { (Afr) }\end{array}$ & Not specified & $\begin{array}{c}\text { Kidney and } \\
\text { bladder ailment }\end{array}$ & {$[42,52]$} \\
\hline Nymphaea nouchali Burm.f. & Nymphaeaceae & $\begin{array}{l}\text { Blue water lily (Eng); } \\
\text { blouwaterlelie (Afr); izubu, iziba, } \\
\text { ugobho (Zulu) }\end{array}$ & Leaves & $\begin{array}{l}\text { Urinary tract } \\
\text { infection }\end{array}$ & {$[46,47,49]$} \\
\hline Ocimum americanum L. & Lamiaceae & $\begin{array}{l}\text { Hoary basil (Eng); wilde } \\
\text { basielkruid (Afr) }\end{array}$ & Not specified & $\begin{array}{l}\text { Urinary tract } \\
\text { infection }\end{array}$ & {$[46]$} \\
\hline $\begin{array}{l}\text { Ocotea bullata (Burch.) } \\
\text { E. Meyer in Drege }\end{array}$ & Lauraceae & $\begin{array}{l}\text { Stinkwood, laurel wood (Eng); } \\
\text { umnukani, umhlungulu (Zulu) }\end{array}$ & Bark & Urinary ailments & {$[43,58]$} \\
\hline Olea europaea L. & Oleaceae & $\begin{array}{l}\text { Wild olive (Eng); olyfhout, } \\
\text { olienhout (Afr); isadlulambezo } \\
\text { (Zulu) }\end{array}$ & $\begin{array}{l}\text { Roots and } \\
\text { bark }\end{array}$ & $\begin{array}{l}\text { Urinary tract } \\
\text { infection }\end{array}$ & {$[43,46]$} \\
\hline Oncoba spinosa Forssk. & Salicaceae & $\begin{array}{c}\text { Snuff-box tree (Eng); } \\
\text { snuifkalbassie (Afr) }\end{array}$ & Not specified & Bladder ailments & {$[42]$} \\
\hline Opuntia ficus-indica (L.) Mill. & Cactaceae & $\begin{array}{l}\text { Foie e kubedu (Sepedi); mudoro } \\
\text { (Venda) }\end{array}$ & Roots & Urinary ailments & {$[63]$} \\
\hline Pedalium murex L. & Pedaliaceae & Large caltrops (Eng) & Leaves & Bladder ailments & {$[42]$} \\
\hline Pegolettia baccharidifolia Less. & Compositae & Ghwarrieson, heuningdou (Afr) & $\begin{array}{l}\text { Leaves and } \\
\text { twigs }\end{array}$ & $\begin{array}{l}\text { Bladder and } \\
\text { kidney ailments }\end{array}$ & {$[44,45]$} \\
\hline $\begin{array}{l}\text { Pelargonium grossularioides } \\
\text { (L.) L'Hér. }\end{array}$ & Geraniaceae & $\begin{array}{l}\text { Rooirabas (Afr); gooseberry- } \\
\text { leaved Pelargonium (Eng) }\end{array}$ & $\begin{array}{l}\text { Leaves and } \\
\text { stems }\end{array}$ & $\begin{array}{l}\text { Urinary tract } \\
\text { infection }\end{array}$ & {$[51,68]$} \\
\hline $\begin{array}{l}\text { Pelargonium hypoleucum } \\
\text { Turcz. }\end{array}$ & Geraniaceae & Rooirabas (Afr) & Roots & $\begin{array}{l}\text { Urinary tract } \\
\text { infection }\end{array}$ & {$[56]$} \\
\hline $\begin{array}{l}\text { Pelargonium ramosissimum } \\
\text { Willd. }\end{array}$ & Geraniaceae & Dassieboegoe, dassiebos (Afr) & $\begin{array}{l}\text { Leaves and } \\
\text { stems }\end{array}$ & $\begin{array}{l}\text { Bladder and } \\
\text { kidney ailments }\end{array}$ & {$[51,68]$} \\
\hline $\begin{array}{l}\text { Pentanisia prunelloides } \\
\text { (Klotzsch) Walp. }\end{array}$ & Rubiaceae & $\begin{array}{l}\text { Sooibrandbossie (Afr); } \\
\text { icimamlilo (Zulu) }\end{array}$ & Roots & $\begin{array}{c}\text { Bladder and } \\
\text { kidney ailments }\end{array}$ & {$[43]$} \\
\hline $\begin{array}{l}\text { Petroselinum crispum (Mill.) } \\
\text { Nyman ex A.W.Hill. }\end{array}$ & Apiaceae & Pietersielie (Afr); parsley (Eng) & Leaves & Bladder ailments & {$[49,66]$} \\
\hline Phytolacca heptandra Retz. & Phytolaccaceae & $\begin{array}{c}\text { Inkbessie (Afr); ingubivumile } \\
\text { (Zulu) }\end{array}$ & Not specified & Urinary ailments & {$[43]$} \\
\hline Portulaca quadrifida $\mathrm{L}$. & Portulacaceae & $\begin{array}{l}\text { Pigweed, wild purslane (Eng); } \\
\text { kanniedood (Afr) }\end{array}$ & Not specified & $\begin{array}{c}\text { Bladder and } \\
\text { kidney ailments }\end{array}$ & {$[42,46]$} \\
\hline Prunus persica (L.) Batsch & Rosaceae & Peach (Eng) & Leaves & Bladder ailments & {$[42]$} \\
\hline Ranunculus multifidus Forssk. & Ranunculaceae & $\begin{array}{l}\text { Botterblom, brandblare (Afr); } \\
\text { uxhaphozi (Zulu) }\end{array}$ & Leaves & Urinary ailments & {$[43]$} \\
\hline Rhamnus prinoides L'Hér. & Rhamnaceae & Mofifi (Sotho) & Root & $\begin{array}{c}\text { Kidney and } \\
\text { bladder ailment }\end{array}$ & {$[54]$} \\
\hline $\begin{array}{l}\text { Rhoicissus tridentata (L.f.) } \\
\text { Wild \& R.B.Drumm. }\end{array}$ & Vitaceae & $\begin{array}{l}\text { Wild/bitter grape (Eng); } \\
\text { bobbejaantou, wildedruif (Afr); } \\
\text { isinwazi (Zulu) }\end{array}$ & Stems & Urinary ailments & {$[43,64]$} \\
\hline $\begin{array}{l}\text { Rhynchosia caribaea (Jacq.) } \\
\text { DC. }\end{array}$ & Leguminosae & $\begin{array}{l}\text { Snoutbean (Eng); rankboontjie } \\
\text { (Afr); isihlahlasenqomfi (Zulu) }\end{array}$ & Roots & Urinary ailments & {$[46]$} \\
\hline Rhynchosia minima (L.) DC. & Leguminosae & $\begin{array}{l}\text { Least snoutbean, burn-mouth- } \\
\text { vine (Eng) }\end{array}$ & Roots & Bladder ailments & {$[46]$} \\
\hline
\end{tabular}


TABLE 1: Continued.

\begin{tabular}{|c|c|c|c|c|c|}
\hline Plant species & Family & Common name & $\begin{array}{l}\text { Part of plant } \\
\text { used }\end{array}$ & Uses & References \\
\hline $\begin{array}{l}\text { Rhynchosia sublobata } \\
\text { (Schum.) Meikle }\end{array}$ & Leguminosae & Twiner of barren ground (Eng) & Roots & Bladder ailments & {$[46]$} \\
\hline Ricinus communis $\mathrm{L}$. & Euphorbiaceae & Olieboom, olieblaar (Afr) & Leaves & $\begin{array}{l}\text { Urinary and } \\
\text { kidney ailments }\end{array}$ & {$[47,50]$} \\
\hline $\begin{array}{l}\text { Rotheca hirsuta (Hochst.) } \\
\text { R.Fern }\end{array}$ & Lamiaceae & $\begin{array}{l}\text { Butterfly bush, wild violet (Eng); } \\
\text { umathanjana, lusikisiki (Zulu) }\end{array}$ & Not specified & Urinary ailments & {$[64]$} \\
\hline Ruta graveolens L. & Rutaceae & Wynruit (Afr) & Leaves & $\begin{array}{l}\text { Urinary tract } \\
\text { infection and } \\
\text { bladder ailments }\end{array}$ & {$[49,56]$} \\
\hline Salix woodii Seemen & Salicaceae & Wild willow (Eng) & Bark & Urinary ailments & [69] \\
\hline Salix mucronata Thunb. & Salicaceae & $\begin{array}{c}\text { Cape willow (Eng); vaalwilger } \\
\text { (Afr) }\end{array}$ & Bark & Bladder ailments & {$[46]$} \\
\hline Salvadora persica L. & Salvadoraceae & $\begin{array}{l}\text { Toothbrush tree, real mustard } \\
\text { tree (Eng); kerriebos (Afr) }\end{array}$ & Roots & $\begin{array}{l}\text { Urinary tract } \\
\text { infection }\end{array}$ & {$[46]$} \\
\hline Salvia microphylla Kunth & Lamiaceae & $\begin{array}{c}\text { Baby sage, Graham's sage, } \\
\text { blackcurrant sage (Eng) }\end{array}$ & Roots & Urinary ailments & {$[50]$} \\
\hline $\begin{array}{l}\text { Scadoxus puniceus (L.) Friis \& } \\
\text { Nordal }\end{array}$ & Amaryllidaceae & $\begin{array}{l}\text { Idumbe likahloyile, uhloyile, } \\
\text { umphompo (Zulu) }\end{array}$ & Not specified & Urinary ailments & {$[47]$} \\
\hline Solanum aculeastrum Dunal & Solanaceae & $\begin{array}{l}\text { Gifappel (Afr); umthuma, } \\
\text { untumane (Zulu) }\end{array}$ & Fruit & $\begin{array}{l}\text { Urinary tract } \\
\text { infection and } \\
\text { kidney ailments }\end{array}$ & {$[47,48]$} \\
\hline $\begin{array}{l}\text { Sutherlandia frutescens (L.) } \\
\text { R.Br. }\end{array}$ & Fabaceae & Keurtjies, kankerbossie (Afr) & $\begin{array}{l}\text { Leaves and } \\
\text { stems }\end{array}$ & $\begin{array}{c}\text { Bladder and } \\
\text { kidney ailments }\end{array}$ & [49] \\
\hline $\begin{array}{l}\text { Tarchonanthus camphoratus } \\
\text { L. }\end{array}$ & Compositae & $\begin{array}{c}\text { Camphor bush (Eng); wilde } \\
\text { kanferbos (Afr); igceba elimhlope } \\
\text { (Zulu) }\end{array}$ & Not specified & Urinary ailments & {$[64]$} \\
\hline Teucrium trifidum Retz. & Lamiaceae & Katjiedriebaar (Afr) & Leaves & Bladder ailments & {$[56,57]$} \\
\hline Thesium hystrix A.W.Hill & Santalaceae & Kleinswartstorm (Afr) & Roots & Bladder ailments & [42] \\
\hline Tragia meyeriana Müll.Arg. & Euphorbiaceae & $\begin{array}{l}\text { Stinging nettle (Eng); ubangalala, } \\
\text { imbabazane (Zulu) }\end{array}$ & Not specified & Bladder ailments & {$[42,43]$} \\
\hline Tragia rupestris Sond. & Euphorbiaceae & Ubangalala, imbabazane (Zulu) & Roots & Bladder ailments & {$[43]$} \\
\hline Trichilia emetica Vahl & Meliaceae & $\begin{array}{l}\text { Red rash (Eng); basteressenhout } \\
\text { (Afr); ixolo, umkhuhlu (Zulu) }\end{array}$ & Bark & Kidney ailments & [43] \\
\hline Trifolium africanum Ser. & Leguminosae & $\begin{array}{l}\text { Erasmus clover, wild clover } \\
\text { (Eng); wildeklawer (Afr); } \\
\text { moqoiqoi, moqophi (Sesotho) }\end{array}$ & Not specified & Bladder ailments & {$[63]$} \\
\hline $\begin{array}{l}\text { Typha capensis (Rohrb.) } \\
\text { N.E.Br. }\end{array}$ & Typhaceae & Papkuil (Afr) & Not specified & $\begin{array}{c}\text { Bladder and } \\
\text { kidney ailments }\end{array}$ & {$[46]$} \\
\hline Urtica urens L. & Urticaceae & $\begin{array}{l}\text { Small nettle (Eng); dog nettle } \\
\text { Eng) }\end{array}$ & Bark & Bladder pains & {$[58]$} \\
\hline $\begin{array}{l}\text { Warburgia salutaris } \\
\text { (G.Bertol.) Chiov. }\end{array}$ & Canellaceae & Isibaha (Zulu) & Leaves & Urethral ailments & {$[67]$} \\
\hline $\begin{array}{l}\text { Withania somnifera (L.) } \\
\text { Dunal }\end{array}$ & Solanaceae & $\begin{array}{l}\text { Winter cherry (Eng); geneesblaar } \\
\text { (Afr) }\end{array}$ & Roots & Bladder ailments & {$[46]$} \\
\hline Xanthium strumarium L. & Compositae & Kankerroos (Afr) & Not specified & Bladder ailments & {$[42]$} \\
\hline $\begin{array}{l}\text { Xysmalobium undulatum (L.) } \\
\text { W.T.Aiton }\end{array}$ & Apocynaceae & Wild cotton (Eng); melkbos (Afr) & Not specified & Bladder ailments & {$[46]$} \\
\hline $\begin{array}{l}\text { Zantedeschia albomaculata } \\
\text { (Hook.) Baill. }\end{array}$ & Araceae & $\begin{array}{l}\text { Arum lilies, calla lilies, pig lily } \\
\text { (Eng.); varkblom (Afr); } \\
\text { mohalalitoe (Sotho) }\end{array}$ & Not specified & Urinary ailments & {$[54,62-64]$} \\
\hline Zea mays L. & Poaceae & Corn (Eng); umbila (Zulu) & Not specified & Bladder ailments & {$[42]$} \\
\hline
\end{tabular}

Microsoft Excel was used for statistical data analysis.

\section{Results}

3.1. Plants Used Traditionally to Treat Urinary Tract Infections. Numerous South African plant species have been recorded to treat pathogenic diseases. This knowledge has traditionally been passed down from generation to generation by word of mouth, and some of this knowledge has now been recorded in ethnobotanical publications, although it is likely that substantial information is not yet readily available. A total of 153 plants from fifty-two families were recorded in the literature for the treatment of UTIs (Table 1). Out of the fifty-two families, Compositae had the greatest 
TABLE 2: Plant species with noteworthy activity that have been tested against urinary tract bacterial pathogens.

\begin{tabular}{|c|c|c|c|c|c|}
\hline Plant species & $\begin{array}{l}\text { Plant part } \\
\text { used }\end{array}$ & $\begin{array}{c}\text { Pathogens } \\
\text { screened }\end{array}$ & MIC values & Toxicity evaluation & References \\
\hline Acacia karoo Hayne & Leaves & E. coli & (M) $414 \mu \mathrm{g} / \mathrm{mL} ;(\mathrm{W}) 458 \mu \mathrm{g} / \mathrm{mL}$ & $\begin{array}{c}\text { Non-toxic in Artemia } \\
\text { lethality assay }\end{array}$ & {$[71]$} \\
\hline Acacia nicolitica (L.) Delile & $\begin{array}{l}\text { Root and } \\
\text { bark }\end{array}$ & E. coli & $\begin{array}{c}\text { Root and bark: (E) } 780 \mu \mathrm{g} / \mathrm{mL} \text {; (W) } \\
6250 \mu \mathrm{g} / \mathrm{mL}\end{array}$ & Not determined & {$[72]$} \\
\hline Acacia sieberiana DC. & $\begin{array}{l}\text { Root and } \\
\text { bark }\end{array}$ & E. coli & $\begin{array}{c}\text { Root and bark: (E) } 92-780 \mu \mathrm{g} / \mathrm{mL} \text {; (W) } \\
1560 \mu \mathrm{g} / \mathrm{mL}\end{array}$ & Not determined & {$[72]$} \\
\hline Agathosma betulina (Berg.) & & E. coli & $(\mathrm{W})>8000 \mu \mathrm{g} / \mathrm{mL}$ & $\begin{array}{l}\text { Not toxic in human } \\
\text { epithelial kidney cells }\end{array}$ & {$[73]$} \\
\hline Pillans & Leaves & $\begin{array}{l}\text { K. pneumoniae } \\
\text { P. mirabilis }\end{array}$ & $\begin{array}{c}\text { (M) } 1876 \mu \mathrm{g} / \mathrm{mL} ;(\mathrm{W}) 2387 \mu \mathrm{g} / \mathrm{mL} \\
(\mathrm{M}) 878 \mu \mathrm{g} / \mathrm{mL}\end{array}$ & $\begin{array}{c}\text { Non-toxic in Artemia } \\
\text { lethality assay }\end{array}$ & $\begin{array}{l}{[41]} \\
{[40]}\end{array}$ \\
\hline $\begin{array}{l}\text { Alchornea cordifolia } \\
\text { (Schumach. And Thonn.) } \\
\text { Müll. Arg. }\end{array}$ & $\begin{array}{l}\text { Leaves, } \\
\text { stem }\end{array}$ & $\begin{array}{l}\text { E. coli } \\
\text { K. pneumoniae } \\
\text { P. mirabilis } \\
\text { S. } \\
\text { saprophyticus }\end{array}$ & $\begin{array}{l}\text { Leaves: (M) } 63 \mu \mathrm{g} / \mathrm{mL} \text {; (E) } 63 \mu \mathrm{g} / \mathrm{mL} \\
\text { Stem (M) } 63 \mu \mathrm{g} / \mathrm{mL} \text {; (E) } 63 \mu \mathrm{g} / \mathrm{mL} \\
\text { Leaves: (M) } 125 \mu \mathrm{g} / \mathrm{mL} \text {; (E) } 125 \mu \mathrm{g} / \mathrm{mL} \\
\text { Stem (M) } 125 \mu \mathrm{g} / \mathrm{mL} \text {; (E) } 125 \mu \mathrm{g} / \mathrm{mL} \\
\text { Leaves: (M) } 125 \mu \mathrm{g} / \mathrm{mL} \text {; (E) } 125 \mu \mathrm{g} / \mathrm{mL} \\
\text { Stem (M) } 125 \mu \mathrm{g} / \mathrm{mL} \text {; (E) } 250 \mu \mathrm{g} / \mathrm{mL} \\
\text { Leaves: (M) } 63 \mu \mathrm{g} / \mathrm{mL} \text {; (E) } 63 \mu \mathrm{g} / \mathrm{mL} \\
\text { Stem (M) } 63 \mu \mathrm{g} / \mathrm{mL} \text {; (E) } 63 \mu \mathrm{g} / \mathrm{mL}\end{array}$ & Not determined & {$[74]$} \\
\hline $\begin{array}{l}\text { Alchornea laxiflora (Benth.) } \\
\text { Pax \& Hoffm. }\end{array}$ & $\begin{array}{l}\text { Leaves, } \\
\text { roots, } \\
\text { stem }\end{array}$ & $\begin{array}{l}\text { E. coli } \\
\text { K. pneumoniae } \\
\text { P. mirabilis } \\
\text { S. } \\
\text { saprophyticus }\end{array}$ & $\begin{array}{c}\text { Leaves: (M) } 125 \mu \mathrm{g} / \mathrm{mL} \text {; (E) } 125 \mu \mathrm{g} / \mathrm{mL} \\
\text { Roots: (M) } 500 \mu \mathrm{g} / \mathrm{mL} \text {; (E) } 500 \mu \mathrm{g} / \mathrm{mL} \\
\text { Stem: (M) } 500 \mu \mathrm{g} / \mathrm{mL} \text {; (E) } 250 \mu \mathrm{g} / \mathrm{mL} \\
\text { Leaves: (M) } 63 \mu \mathrm{g} / \mathrm{mL} \text {; (E) } 63 \mu \mathrm{g} / \mathrm{mL} \\
\text { Roots: (M) } 125 \mu \mathrm{g} / \mathrm{mL} \text {; (E) } 125 \mu \mathrm{g} / \mathrm{mL} \\
\text { Stem: (M) } 500 \mu \mathrm{g} / \mathrm{mL} \text {; (E) } 500 \mu \mathrm{g} / \mathrm{mL} \\
\text { Leaves: (M) } 8000 \mu \mathrm{g} / \mathrm{mL} \text {; (E) } 2000 \mu \mathrm{g} / \\
\mathrm{mL} \\
\text { Roots: (M) } 250 \mu \mathrm{g} / \mathrm{mL} \text {; (E) } 250 \mu \mathrm{g} / \mathrm{mL} \\
\text { Stem: (M) } 4000 \mu \mathrm{g} / \mathrm{mL} \text {; (E) } 4000 \mu \mathrm{g} / \mathrm{mL} \\
\text { Leaves: (M) } 63 \mu \mathrm{g} / \mathrm{mL} \text {; (E) } 63 \mu \mathrm{g} / \mathrm{mL} \\
\text { Roots: (M) } 63 \mu \mathrm{g} / \mathrm{mL} \text {; (E) } 63 \mu \mathrm{g} / \mathrm{mL} \\
\text { Stem: (M) } 63 \mu \mathrm{g} / \mathrm{mL;} \mathrm{(E)} 63 \mu \mathrm{g} / \mathrm{mL}\end{array}$ & $\begin{array}{c}\mathrm{LC}_{50}=100-140 \mu \mathrm{g} / \mathrm{mL} \text { in } \\
\text { HeLa cells }\end{array}$ & {$[74]$} \\
\hline Aloe ferox Mill. & Leaves & E. coli & $(\mathrm{W})>8000 \mu \mathrm{g} / \mathrm{mL}$ & $\begin{array}{l}\text { Not toxic in human } \\
\text { epithelial kidney cells }\end{array}$ & {$[73]$} \\
\hline Aloe marlothii A.Berger & Leaves & $\begin{array}{c}\text { E. coli } \\
\text { P. aeruginosa }\end{array}$ & $\begin{array}{l}\text { (M) } 1250 \mu \mathrm{g} / \mathrm{mL} \\
\text { (M) } 1250 \mu \mathrm{g} / \mathrm{mL}\end{array}$ & Not determined & {$[75]$} \\
\hline $\begin{array}{l}\text { Apodytes dimidiata E.Mey } \\
\text { ex am. }\end{array}$ & Not stated & $\begin{array}{c}\text { E. coli } \\
\text { P. aeruginosa }\end{array}$ & $\begin{array}{l}\text { (A) } 2500 \mu \mathrm{g} / \mathrm{mL} \\
\text { (A) } 310 \mu \mathrm{g} / \mathrm{mL}\end{array}$ & Not determined & {$[76]$} \\
\hline $\begin{array}{l}\text { Artemisia afra Jacq. Ex } \\
\text { Willd. }\end{array}$ & Leaves & E. coli & (W) $3000 \mu \mathrm{g} / \mathrm{mL}$ & $\begin{array}{l}\text { Not toxic in human } \\
\text { epithelial kidney cells }\end{array}$ & {$[74]$} \\
\hline Ballota africana (L.) Benth. & Leaves & $\begin{array}{l}\text { K. pneumoniae } \\
\text { P. mirabilis }\end{array}$ & $\begin{array}{c}\text { (M) } 438 \mu \mathrm{g} / \mathrm{mL} ;(\mathrm{W}) 379 \mu \mathrm{g} / \mathrm{mL} \\
\text { (M) } 4278 \mu \mathrm{g} / \mathrm{mL}\end{array}$ & $\begin{array}{c}\text { Non-toxic in Artemia } \\
\text { lethality assay }\end{array}$ & $\begin{array}{l}41] \\
{[40]} \\
\end{array}$ \\
\hline $\begin{array}{l}\text { Bolosanthus speciosis } \\
\text { (Bolus) Harms }\end{array}$ & Leaves & E. coli & (A) $80 \mu \mathrm{g} / \mathrm{mL}$ & $\begin{array}{c}\mathrm{LC}_{50}=53 \mu \mathrm{g} / \mathrm{mL} \text { in Vero } \\
\text { cells }\end{array}$ & {$[77]$} \\
\hline Brachylaena discolor & Not stated & $\begin{array}{c}\text { E. coli } \\
\text { P. aeruginosa }\end{array}$ & $\begin{array}{l}\text { (A) } 630 \mu \mathrm{g} / \mathrm{mL} \\
\text { (A) } 310 \mu \mathrm{g} / \mathrm{mL}\end{array}$ & Not determined & {$[76]$} \\
\hline $\begin{array}{l}\text { Calpurnia aurea (aiton) } \\
\text { Benth. }\end{array}$ & Leaves & E. coli & (A) $40 \mu \mathrm{g} / \mathrm{mL}$ & $\begin{array}{c}\mathrm{LC} 50=57 \mu \mathrm{g} / \mathrm{mL} \text { in Vero } \\
\text { cells }\end{array}$ & {$[77]$} \\
\hline $\begin{array}{l}\text { Carpobrotus edulis (L.) N.E. } \\
\text { Br. }\end{array}$ & Leaves & $\begin{array}{l}\text { P. mirabilis } \\
\text { Proteus } \\
\text { vulgaris } \\
\end{array}$ & $\begin{array}{l}\text { (M) } 205 \mu \mathrm{g} / \mathrm{mL} \text {; (W) } 561 \mu \mathrm{g} / \mathrm{mL} \\
\text { (M) } 670 \mu \mathrm{g} / \mathrm{mL} \text {; (W) } 1246 \mu \mathrm{g} / \mathrm{mL}\end{array}$ & $\begin{array}{c}\text { Non-toxic in Artemia } \\
\text { lethality assay }\end{array}$ & {$[40]$} \\
\hline $\begin{array}{l}\text { Cissius quadrangularis } \\
\text { (Linn.) }\end{array}$ & Stems & $\begin{array}{c}\text { E. coli } \\
\text { P. aeruginosa }\end{array}$ & $\begin{array}{l}\text { (M) } 1259 \mu \mathrm{g} / \mathrm{mL} \\
\text { (M) } 2500 \mu \mathrm{g} / \mathrm{mL}\end{array}$ & Not determined & {$[75]$} \\
\hline $\begin{array}{l}\text { Clausena anisata (Willd.) } \\
\text { Hook ex Benth. }\end{array}$ & Not stated & $\begin{array}{c}\text { E. coli } \\
\text { P. aeruginosa } \\
\end{array}$ & $\begin{array}{l}\text { (A) } 310 \mu \mathrm{g} / \mathrm{mL} \\
\text { (A) } 310 \mu \mathrm{g} / \mathrm{mL} \\
\end{array}$ & Not determined & {$[76]$} \\
\hline $\begin{array}{l}\text { Clerodendron glabrum } \\
\text { E.Mey }\end{array}$ & Not stated & $\begin{array}{c}\text { E. coli } \\
\text { P. aeruginosa }\end{array}$ & $\begin{array}{l}\text { (A) } 310 \mu \mathrm{g} / \mathrm{mL} \\
\text { (A) } 630 \mu \mathrm{g} / \mathrm{mL}\end{array}$ & Not determined & {$[76]$} \\
\hline
\end{tabular}


TABle 2: Continued.

\begin{tabular}{|c|c|c|c|c|c|}
\hline Plant species & $\begin{array}{l}\text { Plant part } \\
\text { used }\end{array}$ & $\begin{array}{l}\text { Pathogens } \\
\text { screened }\end{array}$ & MIC values & Toxicity evaluation & References \\
\hline $\begin{array}{l}\text { Combretum kraussii } \\
\text { Hochst. }\end{array}$ & Leaves & E. coli & $\begin{array}{l}\text { Root and bark: (E) } 1560 \mu \mathrm{g} / \mathrm{mL} ;(\mathrm{W}) \\
3125 \mu \mathrm{g} / \mathrm{mL}\end{array}$ & Not determined & {$[72]$} \\
\hline $\begin{array}{l}\text { Cremaspora triflora } \\
\text { (Thonn.) K.Schum. }\end{array}$ & Leaves & E. coli & (A) $50 \mu \mathrm{g} / \mathrm{mL}$ & $\begin{array}{c}\mathrm{LC}_{50}=14 \mu \mathrm{g} / \mathrm{mL} \text { in Vero } \\
\text { cells }\end{array}$ & {$[77]$} \\
\hline Cryptocarya latifolia Sond. & Bark & P. aeruginosa & $\begin{array}{c}\text { (M) } 4000 \mu \mathrm{g} / \mathrm{mL} \text {; (W) }>8000 \mu \mathrm{g} / \mathrm{mL} \\
\text { (D) }>8000 \mu \mathrm{g} / \mathrm{mL} ;(\mathrm{EA})>8000 \mu \mathrm{g} / \mathrm{mL} ; \\
\text { (H) }>8000 \mu \mathrm{g} / \mathrm{mL} \\
\text { (M) } 4000 \mu \mathrm{g} / \mathrm{mL} ;(\mathrm{W})>8000 \mu \mathrm{g} / \mathrm{mL} \\
\text { (D) }>8000 \mu \mathrm{g} / \mathrm{mL} ;(\mathrm{EA}) 2000 \mu \mathrm{g} / \mathrm{mL} \\
\text { (H) } 4000 \mu \mathrm{g} / \mathrm{mL}\end{array}$ & Not determined & {$[78]$} \\
\hline $\begin{array}{l}\text { Curtisia dentata (Burm.f) } \\
\text { C.A. Sm. }\end{array}$ & Not stated & $\begin{array}{c}\text { E. coli } \\
\text { P. aeruginosa }\end{array}$ & $\begin{array}{l}\text { (A) } 600 \mu \mathrm{g} / \mathrm{mL} \\
\text { (A) } 600 \mu \mathrm{g} / \mathrm{mL}\end{array}$ & Not determined & {$[79]$} \\
\hline Cussonia spicata Thunb. & Bark & $\begin{array}{c}\text { E. coli } \\
\text { P. aeruginosa }\end{array}$ & $\begin{array}{l}\text { (M) } 1250 \mu \mathrm{g} / \mathrm{mL} \\
\text { (M) } 1250 \mu \mathrm{g} / \mathrm{mL}\end{array}$ & Not determined & {$[75]$} \\
\hline Cussonia zuluensis Strey. & Not stated & $\begin{array}{c}\text { E. coli } \\
\text { P. aeruginosa }\end{array}$ & $\begin{array}{l}\text { (A) } 880 \mu \mathrm{g} / \mathrm{mL} \\
\text { (A) } 880 \mu \mathrm{g} / \mathrm{mL}\end{array}$ & Not determined & {$[79]$} \\
\hline $\begin{array}{l}\text { Cyathea dregei (Kunze.) } \\
\text { R.M.Tyron }\end{array}$ & Not stated & $\begin{array}{c}\text { E. coli } \\
\text { P. aeruginosa }\end{array}$ & $\begin{array}{l}\text { (A) } 310 \mu \mathrm{g} / \mathrm{mL} \\
\text { (A) } 310 \mu \mathrm{g} / \mathrm{mL}\end{array}$ & Not determined & {$[76]$} \\
\hline $\begin{array}{l}\text { Dicerocaryum ericarpum } \\
\text { (Decne.) }\end{array}$ & Shoots & $\begin{array}{c}\text { E. coli } \\
\text { P. aeruginosa }\end{array}$ & $\begin{array}{l}\text { (M) } 1250 \mu \mathrm{g} / \mathrm{mL} \\
\text { (M) } 1250 \mu \mathrm{g} / \mathrm{mL} \\
\end{array}$ & Not determined & {$[75]$} \\
\hline Ekebergia capensi Sparrm. & Leaves & E. coli & $\begin{array}{c}\text { (M) } 1000 \mu \mathrm{g} / \mathrm{mL} ;(\mathrm{W})>8000 \mu \mathrm{g} / \mathrm{mL} \\
\text { (D) } 1000 \mu \mathrm{g} / \mathrm{mL}\end{array}$ & $\begin{array}{c}\text { Non-toxic in Artemia } \\
\text { lethality assay }\end{array}$ & {$[80]$} \\
\hline $\begin{array}{l}\text { Ekebergia pterophylla } \\
\text { (C.DC) Hofmeyr }\end{array}$ & Leaves & E. coli & $\begin{array}{c}\text { (M) } 1000 \mu \mathrm{g} / \mathrm{mL} ;(\mathrm{W})>8000 \mu \mathrm{g} / \mathrm{mL} ; \\
\text { (D) } 4000 \mu \mathrm{g} / \mathrm{mL}\end{array}$ & $\begin{array}{c}\text { Non-toxic in Artemia } \\
\text { lethality assay }\end{array}$ & {$[80]$} \\
\hline $\begin{array}{l}\text { Elaeodendron croceum } \\
\text { (Thunb.) DC. }\end{array}$ & Leaves & E. coli & (A) $110 \mu \mathrm{g} / \mathrm{mL}$ & $\begin{array}{c}\mathrm{LC}_{50}=5 \mu \mathrm{g} / \mathrm{mL} \text { in Vero } \\
\text { cells }\end{array}$ & {$[77]$} \\
\hline $\begin{array}{l}\text { Euclea crispa (Thunb.) } \\
\text { Gürke }\end{array}$ & Leaf & $\begin{array}{c}\text { E. coli } \\
\text { P. aeruginosa }\end{array}$ & $\begin{array}{c}\text { (M) } 1750 \mu \mathrm{g} / \mathrm{mL} \text {; (D) } 1750 \mu \mathrm{g} / \mathrm{mL} \\
\text { (EA) } 1280 \mu \mathrm{g} / \mathrm{mL} \\
\text { (M) } 2000 \mu \mathrm{g} / \mathrm{mL} ;(\mathrm{D}) 2000 \mu \mathrm{g} / \mathrm{mL} \\
\text { (EA) } 1500 \mu \mathrm{g} / \mathrm{mL}\end{array}$ & Not determined & {$[81]$} \\
\hline Euclea natalensis A. DC. & Leaf & $\begin{array}{c}\text { E. coli } \\
\text { P. aeruginosa }\end{array}$ & $\begin{array}{c}\text { (M) } 1250 \mu \mathrm{g} / \mathrm{mL} ;(\mathrm{D}) 1750 \mu \mathrm{g} / \mathrm{mL} \\
\text { (EA) } 1380 \mu \mathrm{g} / \mathrm{mL} \\
\text { (M) } 1000 \mu \mathrm{g} / \mathrm{mL} ;(\mathrm{D}) 2000 \mu \mathrm{g} / \mathrm{mL} \\
\text { (EA) } 2000 \mu \mathrm{g} / \mathrm{mL}\end{array}$ & Not determined & {$[81]$} \\
\hline $\begin{array}{l}\text { Eucomis autumnalis (Mill.) } \\
\text { Chitt. }\end{array}$ & Bulb & $\begin{array}{c}\text { E. coli } \\
\text { P. aeruginosa }\end{array}$ & $\begin{array}{c}\text { (M) }>8000 \mu \mathrm{g} / \mathrm{mL} ;(\mathrm{W})>8000 \mu \mathrm{g} / \mathrm{mL} \\
(\mathrm{D})>8000 \mu \mathrm{g} / \mathrm{mL} ;(\mathrm{EA})>8000 \mu \mathrm{g} / \mathrm{mL} ; \\
(\mathrm{H})>8000 \mu \mathrm{g} / \mathrm{mL} \\
(\mathrm{M})>8000 \mu \mathrm{g} / \mathrm{mL} ;(\mathrm{W})>8000 \mu \mathrm{g} / \mathrm{mL} ; \\
(\mathrm{D})>8000 \mu \mathrm{g} / \mathrm{mL} ;(\mathrm{EA})>8000 \mu \mathrm{g} / \mathrm{mL} ; \\
\text { (H) } 2000 \mu \mathrm{g} / \mathrm{mL}\end{array}$ & Not determined & {$[78]$} \\
\hline Ficus sur Forssk. & $\begin{array}{l}\text { Root and } \\
\text { bark }\end{array}$ & E. coli & $\begin{array}{l}\text { Root and bark: (E) } 1560 \mu \mathrm{g} / \mathrm{mL} \text {; (W) } \\
4600 \mu \mathrm{g} / \mathrm{mL}\end{array}$ & Not determined & {$[72]$} \\
\hline $\begin{array}{l}\text { Gymnosporia senegalensis } \\
\text { (Lam.) Loes. }\end{array}$ & Roots & E. coli & $\begin{array}{l}\text { (M) } 156 \mu \mathrm{g} / \mathrm{mL} \text {; (W) } 312 \mu \mathrm{g} / \mathrm{mL} \text {; (E) } \\
156 \mu \mathrm{g} / \mathrm{mL} \text {; (A) } 312 \mu \mathrm{g} / \mathrm{mL}\end{array}$ & Not determined & {$[82]$} \\
\hline Hydnora africana Thunb. & Bark & P. aeruginosa & $\begin{array}{c}\text { (M) }>8000 \mu \mathrm{g} / \mathrm{mL} ;(\mathrm{W})>8000 \mu \mathrm{g} / \mathrm{mL} ; \\
\text { (D) }>8000 \mu \mathrm{g} / \mathrm{mL} ;(\mathrm{EA})>8000 \mu \mathrm{g} / \mathrm{mL} ; \\
(\mathrm{H})>8000 \mu \mathrm{g} / \mathrm{mL} \\
\text { (M) } 2000 \mu \mathrm{g} / \mathrm{mL} ;(\mathrm{W})>8000 \mu \mathrm{g} / \mathrm{mL} ; \\
\text { (D) }>8000 \mu \mathrm{g} / \mathrm{mL} ;(\mathrm{EA})>8000 \mu \mathrm{g} / \mathrm{mL} ; \\
\quad(\mathrm{H})>8000 \mu \mathrm{g} / \mathrm{mL}\end{array}$ & Not determined & {$[78]$} \\
\hline $\begin{array}{l}\text { Heteromorpha arborescens } \\
\text { (Spreng.) Cham \& Schltdl. }\end{array}$ & Leaves & E. coli & (A) $180 \mu \mathrm{g} / \mathrm{mL}$ & $\begin{array}{c}\mathrm{LC}_{50}=81 \mu \mathrm{g} / \mathrm{mL} \text { in Vero } \\
\text { cells }\end{array}$ & {$[77]$} \\
\hline $\begin{array}{l}\text { Hetromorpha trifoliata } \\
\text { Wendl. Eckl. \& Zeyh. }\end{array}$ & Not stated & $\begin{array}{c}\text { E.coli } \\
\text { P. aeruginosa }\end{array}$ & $\begin{array}{l}\text { (A) } 630 \mu \mathrm{g} / \mathrm{mL} \\
\text { (A) } 630 \mu \mathrm{g} / \mathrm{mL}\end{array}$ & Not determined & {$[76]$} \\
\hline
\end{tabular}


TABle 2: Continued.

\begin{tabular}{|c|c|c|c|c|c|}
\hline Plant species & $\begin{array}{l}\text { Plant part } \\
\text { used }\end{array}$ & $\begin{array}{l}\text { Pathogens } \\
\text { screened }\end{array}$ & MIC values & Toxicity evaluation & References \\
\hline Heteropyxis natalensis Harv. & Leaves & E. coli & (M) $382 \mu \mathrm{g} / \mathrm{mL}$ & $\begin{array}{c}\text { Non-toxic in Artemia } \\
\text { lethality assay }\end{array}$ & {$[71]$} \\
\hline $\begin{array}{l}\text { Hypericim roeperianum } \\
\text { G.W.Schimp. ex A. Rich. }\end{array}$ & Leaves & E. coli & (A) $130 \mu \mathrm{g} / \mathrm{mL}$ & $\begin{array}{c}\mathrm{LC}_{50}=66 \mu \mathrm{g} / \mathrm{mL} \text { in Vero } \\
\text { cells }\end{array}$ & {$[77]$} \\
\hline $\begin{array}{l}\text { Hypoxis hemerocallidea } \\
\text { Fisch.Mey. \& avé-Lall. }\end{array}$ & Leaves & $\begin{array}{c}\text { E. coli } \\
\text { P. aeruginosa }\end{array}$ & $\begin{array}{c}\text { (M) } 4000 \mu \mathrm{g} / \mathrm{mL} ;(\mathrm{W}) 4000 \mu \mathrm{g} / \mathrm{mL} ;(\mathrm{D}) \\
>8000 \mu \mathrm{g} / \mathrm{mL} ;(\mathrm{EA})>8000 \mu \mathrm{g} / \mathrm{mL} \\
(\mathrm{H})>8000 \mu \mathrm{g} / \mathrm{mL} \\
(\mathrm{M})>8000 \mu \mathrm{g} / \mathrm{mL} ;(\mathrm{W})>8000 \mu \mathrm{g} / \mathrm{mL} \\
(\mathrm{D})>8000 \mu \mathrm{g} / \mathrm{mL} ;(\mathrm{EA})>8000 \mu \mathrm{g} / \mathrm{mL} ; \\
(\mathrm{H})>8000 \mu \mathrm{g} / \mathrm{mL}\end{array}$ & Not determined & {$[78]$} \\
\hline Indigofera daleoides Harv. & $\begin{array}{l}\text { Whole } \\
\text { plant }\end{array}$ & E. coli & $\begin{array}{c}\text { (M) } 78 \mu \mathrm{g} / \mathrm{mL} ;(\mathrm{E}) 146 \mu \mathrm{g} / \mathrm{mL} ;(\mathrm{A}) \\
78 \mu \mathrm{g} / \mathrm{mL}\end{array}$ & Not dertermined & {$[82]$} \\
\hline Indigofera frutescens Linn. $\mathrm{f}$. & Not stated & $\begin{array}{c}\text { E. coli } \\
\text { P. aeruginosa }\end{array}$ & $\begin{array}{l}\text { (A) } 160 \mu \mathrm{g} / \mathrm{mL} \\
\text { (A) } 310 \mu \mathrm{g} / \mathrm{mL}\end{array}$ & Not determined & {$[76]$} \\
\hline Jatropha zeheri Sond. & Root & $\begin{array}{c}\text { E. coli } \\
\text { P. aeruginosa }\end{array}$ & $\begin{array}{l}\text { (M) } 630 \mu \mathrm{g} / \mathrm{mL} \\
\text { (M) } 2500 \mu \mathrm{g} / \mathrm{mL} \\
\end{array}$ & Not determined & {$[75]$} \\
\hline $\begin{array}{l}\text { Kigelia africana (Lam.) } \\
\text { Benth. }\end{array}$ & Leaves & $\begin{array}{c}\text { E. coli } \\
\text { K. pneumoniae } \\
\text { P. mirabilis }\end{array}$ & $\begin{array}{l}\text { (M) } 827 \mu \mathrm{g} / \mathrm{mL} \text {; (W) } 681 \mu \mathrm{g} / \mathrm{mL} \\
\text { (M) } 965 \mu \mathrm{g} / \mathrm{mL} \text {; (W) } 663 \mu \mathrm{g} / \mathrm{mL} \\
\text { (M) } 2483 \mu \mathrm{g} / \mathrm{mL} \text {; (W) } 285 \mu \mathrm{g} / \mathrm{mL}\end{array}$ & $\begin{array}{c}\text { Non-toxic in Artemia } \\
\text { lethality assay }\end{array}$ & $\begin{array}{l}{[71]} \\
{[41]} \\
{[40]}\end{array}$ \\
\hline $\begin{array}{l}\text { Leucosidea sericea Eckl. \& } \\
\text { Zeyh. }\end{array}$ & Not stated & $\begin{array}{c}\text { E. coli } \\
\text { P. aeruginosa }\end{array}$ & $\begin{array}{l}\text { (A) } 80 \mu \mathrm{g} / \mathrm{mL} \\
\text { (A) } 20 \mu \mathrm{g} / \mathrm{mL}\end{array}$ & Not determined & {$[76]$} \\
\hline $\begin{array}{l}\text { Lippia javanica (Burm.f.) } \\
\text { Spreng. }\end{array}$ & Leaves & $\begin{array}{l}\text { E. coli } \\
\text { K. pneumoniae } \\
\text { P. mirabilis } \\
\text { Proteus } \\
\text { vulgaris }\end{array}$ & $\begin{array}{l}\text { (M) } 439 \mu \mathrm{g} / \mathrm{mL} \text {; (W) } 192 \mu \mathrm{g} / \mathrm{mL} \\
\text { (M) } 538 \mu \mathrm{g} / \mathrm{mL} \text {; (W) } 654 \mu \mathrm{g} / \mathrm{mL} \\
\text { (M) } 313 \mu \mathrm{g} / \mathrm{mL} \text {; (W) } 1873 \mu \mathrm{g} / \mathrm{mL} \\
\text { (M) } 926 \mu \mathrm{g} / \mathrm{mL} \text {; (W) } 1728 \mu \mathrm{g} / \mathrm{mL}\end{array}$ & $\begin{array}{l}\text { Non-toxic in Artemia } \\
\text { lethality assay }\end{array}$ & $\begin{array}{l}{[71]} \\
{[41]} \\
{[40]} \\
{[40]}\end{array}$ \\
\hline Maesa lanceolata Forssk. & Leaves & $\begin{array}{c}\text { E. coli } \\
\text { P. aeruginosa }\end{array}$ & $\begin{array}{l}\text { (A) } 40-310 \mu \mathrm{g} / \mathrm{mL} \\
\text { (A) } 20-310 \mu \mathrm{g} / \mathrm{mL}\end{array}$ & $\begin{array}{c}\mathrm{LC}_{50}=2.4 \mu \mathrm{g} / \mathrm{mL} \text { in Vero } \\
\text { cells }\end{array}$ & {$[76,77]$} \\
\hline $\begin{array}{l}\text { Melletia grandis (E.Mey.) } \\
\text { Skeels }\end{array}$ & Not stated & $\begin{array}{c}\text { E. coli } \\
\text { P. aeruginosa }\end{array}$ & $\begin{array}{l}\text { (A) } 310 \mu \mathrm{g} / \mathrm{mL} \\
\text { (A) } 310 \mu \mathrm{g} / \mathrm{mL}\end{array}$ & Not determined & {$[76]$} \\
\hline Melia azedarach L. & Not stated & $\begin{array}{c}\text { E. coli } \\
\text { P. aeruginosa }\end{array}$ & $\begin{array}{l}\text { (A) } 310 \mu \mathrm{g} / \mathrm{mL} \\
\text { (A) } 630 \mu \mathrm{g} / \mathrm{mL}\end{array}$ & Not determined & {$[76]$} \\
\hline Morus mesozygia Stapf. & Leaves & E. coli & (A) $70 \mu \mathrm{g} / \mathrm{mL}$ & $\begin{array}{c}\mathrm{LC}_{50}=41 \mu \mathrm{g} / \mathrm{mL} \text { in Vero } \\
\text { cells }\end{array}$ & {$[77]$} \\
\hline $\begin{array}{l}\text { Nymania capensis (Thunb.) } \\
\text { Lindb. }\end{array}$ & Leaves & E. coli & $\begin{array}{c}(\mathrm{M})>8000 \mu \mathrm{g} / \mathrm{mL} ;(\mathrm{W})>8000 \mu \mathrm{g} / \mathrm{mL} \\
(\mathrm{D})>8000 \mu \mathrm{g} / \mathrm{mL}\end{array}$ & $\begin{array}{c}\text { Non-toxic in Artemia } \\
\text { lethality assay }\end{array}$ & {$[80]$} \\
\hline Ozoroa insignis Delile & Stem bark & E. coli & $\begin{array}{l}\text { (M) } 156 \mu \mathrm{g} / \mathrm{mL} ;(\mathrm{W}) 156 \mu \mathrm{g} / \mathrm{mL} \text {; (E) } \\
156 \mu \mathrm{g} / \mathrm{mL} ; \text { (A) } 156 \mu \mathrm{g} / \mathrm{mL}\end{array}$ & Not determined & {$[82]$} \\
\hline Pelargonium sidoides DC. & Leaves & E. coli & $(\mathrm{W})>8000 \mu \mathrm{g} / \mathrm{mL}$ & $\begin{array}{c}\text { Non-toxic in Artemia } \\
\text { lethality assay }\end{array}$ & {$[73]$} \\
\hline $\begin{array}{l}\text { Pittosporum viridiflorum } \\
\text { Sims }\end{array}$ & Leaves & E. coli & (A) $110 \mu \mathrm{g} / \mathrm{mL}$ & $\begin{array}{c}\mathrm{LC}_{50}=55 \mu \mathrm{g} / \mathrm{mL} \text { in Vero } \\
\text { cells }\end{array}$ & {$[74]$} \\
\hline $\begin{array}{l}\text { Pelargonium fasiculata (L.) } \\
\text { Alton }\end{array}$ & Leaves & $\begin{array}{l}\text { K. pneumoniae } \\
\text { P. mirabilis }\end{array}$ & $\begin{array}{l}\text { (M) } 374 \mu \mathrm{g} / \mathrm{mL} \text {; (W) } 432 \mu \mathrm{g} / \mathrm{mL} \\
\text { (M) } 806 \mu \mathrm{g} / \mathrm{mL} \text {; (W) } 1843 \mu \mathrm{g} / \mathrm{mL}\end{array}$ & $\begin{array}{c}\text { Non-toxic in Artemia } \\
\text { lethality assay }\end{array}$ & $\begin{array}{l}{[41]} \\
{[40]} \\
\end{array}$ \\
\hline Ptaerocarpus angolensis DC. & Bark & $\begin{array}{c}\text { E. coli } \\
\text { P. aeruginosa }\end{array}$ & $\begin{array}{l}\text { (M) } 630 \mu \mathrm{g} / \mathrm{mL} \\
\text { (M) } 2500 \mu \mathrm{g} / \mathrm{mL} \\
\end{array}$ & Not determined & {$[75]$} \\
\hline $\begin{array}{l}\text { Ptaeroxylon obliquim } \\
\text { (Thunb.) Radlk. }\end{array}$ & Leaves & $\begin{array}{l}\text { K. pneumoniae } \\
\text { P. mirabilis } \\
\text { Proteus } \\
\text { vulgaris }\end{array}$ & $\begin{array}{c}\text { (M) } 1977 \mu \mathrm{g} / \mathrm{mL} \\
\text { (M) } 239 \mu \mathrm{g} / \mathrm{mL} ;(\mathrm{W}) 487 \mu \mathrm{g} / \mathrm{mL} \\
\text { (M) } 511 \mu \mathrm{g} / \mathrm{mL} ;(\mathrm{W}) 727 \mu \mathrm{g} / \mathrm{mL}\end{array}$ & $\begin{array}{l}\text { Non-toxic in Artemia } \\
\text { lethality assay }\end{array}$ & $\begin{array}{l}{[41]} \\
{[40]}\end{array}$ \\
\hline
\end{tabular}


TABle 2: Continued.

\begin{tabular}{|c|c|c|c|c|c|}
\hline Plant species & $\begin{array}{l}\text { Plant part } \\
\text { used }\end{array}$ & $\begin{array}{l}\text { Pathogens } \\
\text { screened }\end{array}$ & MIC values & Toxicity evaluation & References \\
\hline $\begin{array}{l}\text { Prunus africana (Hook. f.) } \\
\text { Kalkman }\end{array}$ & Roots & $\begin{array}{c}\text { E. coli } \\
\text { P. aeruginosa }\end{array}$ & $\begin{array}{c}\text { (M) }>8000 \mu \mathrm{g} / \mathrm{mL} ;(\mathrm{W})>8000 \mu \mathrm{g} / \mathrm{mL} \\
(\mathrm{D})>8000 \mu \mathrm{g} / \mathrm{mL} ;(\mathrm{EA})>8000 \mu \mathrm{g} / \mathrm{mL} \\
(\mathrm{H})>8000 \mu \mathrm{g} / \mathrm{mL} \\
(\mathrm{M})>8000 \mu \mathrm{g} / \mathrm{mL} ;(\mathrm{W})>8000 \mu \mathrm{g} / \mathrm{mL} \\
(\mathrm{D})>8000 \mu \mathrm{g} / \mathrm{mL} ;(\mathrm{EA})>8000 \mu \mathrm{g} / \mathrm{mL} \\
(\mathrm{H})>8000 \mu \mathrm{g} / \mathrm{mL}\end{array}$ & Not determined & {$[78]$} \\
\hline Punica granatum L. & Roots & E. coli & $\begin{array}{c}\text { (M) } 78 \mu \mathrm{g} / \mathrm{mL} ;(\mathrm{W}) 78 \mu \mathrm{g} / \mathrm{mL} \text {; (E) } \\
78 \mu \mathrm{g} / \mathrm{mL} ;(\mathrm{A}) 78 \mu \mathrm{g} / \mathrm{mL}\end{array}$ & Not determined & {$[82]$} \\
\hline Rhicinus communis Linn. & $\begin{array}{c}\text { Leaves } \\
\text { and stem }\end{array}$ & $\begin{array}{c}\text { E. coli } \\
\text { P. aeruginosa }\end{array}$ & $\begin{array}{l}\text { (M) } 400 \mu \mathrm{g} / \mathrm{mL} \\
\text { (M) } 780 \mu \mathrm{g} / \mathrm{mL}\end{array}$ & Not determined & {$[75]$} \\
\hline $\begin{array}{l}\text { Rhoicissus rhomboidea (E. } \\
\text { Mey ex Harv.) Planch. }\end{array}$ & Leaves & E. coli & (M) $306 \mu \mathrm{g} / \mathrm{mL}$; (W) $333 \mu \mathrm{g} / \mathrm{mL}$ & $\begin{array}{c}\text { Non-toxic in Artemia } \\
\text { lethality assay }\end{array}$ & {$[71]$} \\
\hline $\begin{array}{l}\text { Rhoicissus tridentata (L.f.) } \\
\text { Wild \& R.B.Drumm. }\end{array}$ & Roots & $\begin{array}{c}\text { E. coli } \\
\text { P. aeruginosa }\end{array}$ & $\begin{array}{c}\text { (M) }>8000 \mu \mathrm{g} / \mathrm{mL} ;(\mathrm{W})>8000 \mu \mathrm{g} / \mathrm{mL} \\
\text { (D) }>8000 \mu \mathrm{g} / \mathrm{mL} ;(\mathrm{EA})>8000 \mu \mathrm{g} / \mathrm{mL} \\
(\mathrm{H})>8000 \mu \mathrm{g} / \mathrm{mL} \\
\text { (M) } 2000 \mu \mathrm{g} / \mathrm{mL} ;(\mathrm{W})>8000 \mu \mathrm{g} / \mathrm{mL} \\
\text { (D) }>8000 \mu \mathrm{g} / \mathrm{mL} ;(\mathrm{EA})>8000 \mu \mathrm{g} / \mathrm{mL} \\
(\mathrm{H})>8000 \mu \mathrm{g} / \mathrm{mL}\end{array}$ & Not determined & {$[78]$} \\
\hline Riccinus communis $\mathrm{L}$. & Leaves & $\begin{array}{c}\text { E. coli } \\
\text { P. aeruginosa } \\
\text { K. pneumoniae } \\
\end{array}$ & $\begin{array}{c}\text { (A) } 13130 \mu \mathrm{g} / \mathrm{mL} \\
\text { (M) } 14670 \mu \mathrm{g} / \mathrm{mL} ;(\text { E) } 16670 \mu \mathrm{g} / \mathrm{mL} \\
\text { (M) } 12670 \mu \mathrm{g} / \mathrm{mL} \text {; (A) } 11670 \mu \mathrm{g} / \mathrm{mL}\end{array}$ & Not determined & {$[83]$} \\
\hline $\begin{array}{l}\text { Sacrostemma viminale } \mathrm{R} . \\
\text { Br. }\end{array}$ & Stem & $\begin{array}{c}\text { E. coli } \\
\text { P. aeruginosa }\end{array}$ & $\begin{array}{l}\text { (M) } 1250 \mu \mathrm{g} / \mathrm{mL} \\
\text { (M) } 1250 \mu \mathrm{g} / \mathrm{mL} \\
\end{array}$ & Not determined & {$[75]$} \\
\hline Schkuhria pinnata (Lam.) & Shoots & $\begin{array}{c}\text { E. coli } \\
\text { P. aeruginosa }\end{array}$ & $\begin{array}{l}\text { (M) } 310 \mu \mathrm{g} / \mathrm{mL} \\
\text { (M) } 1250 \mu \mathrm{g} / \mathrm{mL} \\
\end{array}$ & Not determined & {$[75]$} \\
\hline Schotia bractopetalia Sond. & Leaves & E. coli & $\begin{array}{c}\text { (M) } 505 \mu \mathrm{g} / \mathrm{mL} \text {; (W) } 312 \mu \mathrm{g} / \mathrm{mL} \text {; (E) } \\
491 \mu \mathrm{g} / \mathrm{mL} \text {; (A) } 312 \mu \mathrm{g} / \mathrm{mL}\end{array}$ & $\begin{array}{c}\text { Non-toxic in Artemia } \\
\text { lethality assay }\end{array}$ & {$[71]$} \\
\hline Spirostachys africana Sond. & Stem bark & E. coli & $\begin{array}{l}\text { (M) } 156 \mu \mathrm{g} / \mathrm{mL} \text {; (W) } 312 \mu \mathrm{g} / \mathrm{mL} \text {; (E) } \\
156 \mu \mathrm{g} / \mathrm{mL} \text {; (A) } 156 \mu \mathrm{g} / \mathrm{mL}\end{array}$ & Not determined & {$[82]$} \\
\hline $\begin{array}{l}\text { Syzygium cordatum } \\
\text { (Hochst.) }\end{array}$ & $\begin{array}{l}\text { Leaves } \\
\text { and bark }\end{array}$ & $\begin{array}{c}\text { E. coli } \\
\text { K. pneumoniae }\end{array}$ & $\begin{array}{c}\text { (M) } 499 \mu \mathrm{g} / \mathrm{mL} ;(\mathrm{W}) 790 \mu \mathrm{g} / \mathrm{mL} \\
\text { (M) } 312 \text { and } 387 \mu \mathrm{g} / \mathrm{mL} \text { (bark and } \\
\text { leaves respectively); (W) } 387 \text { and } \\
335 \mu \mathrm{g} / \mathrm{mL} \text { (bark and leaves } \\
\text { respectively) } \\
\text { (M) } 969 \text { and } 474 \mu \mathrm{g} / \mathrm{mL} \text { (bark and } \\
\text { leaves respectively); (W) } 932 \text { and } \\
49 \mu \mathrm{g} / \mathrm{mL} \text { (bark and leaves } \\
\text { respectively) } \\
\text { (M) } 751 \text { and } 641 \mu \mathrm{g} / \mathrm{mL} \text { (bark and } \\
\text { leaves respectively); (W) } 1325 \text { and } \\
658 \mu \mathrm{g} / \mathrm{mL} \text { (bark and leaves } \\
\text { respectively) }\end{array}$ & $\begin{array}{l}\text { Non-toxic in Artemia } \\
\text { lethality assay }\end{array}$ & [41] \\
\hline $\begin{array}{l}\text { Strychnos madagascariensis } \\
\text { Poir. }\end{array}$ & Leaves & E. coli & (M) $580 \mu \mathrm{g} / \mathrm{mL} ;(\mathrm{W}) 593 \mu \mathrm{g} / \mathrm{mL}$ & $\begin{array}{c}\text { Non-toxic in Artemia } \\
\text { lethality assay }\end{array}$ & {$[71]$} \\
\hline Strychnos mitis S.Moore & Not stated & $\begin{array}{c}\text { E. coli } \\
\text { P. aeruginosa }\end{array}$ & $\begin{array}{l}\text { (A) } 40 \mu \mathrm{g} / \mathrm{mL} \\
\text { (A) } 160 \mu \mathrm{g} / \mathrm{mL}\end{array}$ & Not determined & {$[76]$} \\
\hline $\begin{array}{l}\text { Sutherlandia frutescens (L.) } \\
\text { R.Br. }\end{array}$ & Leaves & E. coli & $(\mathrm{W})>8000 \mu \mathrm{g} / \mathrm{mL}$ & $\begin{array}{l}\text { Not toxic in human } \\
\text { epithelial kidney cells }\end{array}$ & {$[73]$} \\
\hline $\begin{array}{l}\text { Terminalia phanerophlebia } \\
\text { Engl. \& Diels, }\end{array}$ & Not stated & $\begin{array}{c}\text { E. coli } \\
\text { P. aeruginosa }\end{array}$ & $\begin{array}{l}\text { (A) } 80 \mu \mathrm{g} / \mathrm{mL} \\
\text { (A) } 80 \mu \mathrm{g} / \mathrm{mL} \\
\end{array}$ & Not determined & [79] \\
\hline $\begin{array}{l}\text { Terminalia pruinoides M.A. } \\
\text { Lawson }\end{array}$ & Leaves & $\begin{array}{l}\text { E. coli } \\
\text { K. pneumoniae } \\
\text { P. mirabilis } \\
\text { P. vulgaris }\end{array}$ & $\begin{array}{l}\text { (M) } 278 \mu \mathrm{g} / \mathrm{mL} \text {; (W) } 624 \mu \mathrm{g} / \mathrm{mL} \\
\text { (M) } 432 \mu \mathrm{g} / \mathrm{mL} \text {; (W) } 531 \mu \mathrm{g} / \mathrm{mL} \\
\text { (M) } 313 \mu \mathrm{g} / \mathrm{mL} \text { (W) } 224 \mu \mathrm{g} / \mathrm{mL} \\
\text { (M) } 926 \mu \mathrm{g} / \mathrm{mL} \text { (W) } 379 \mu \mathrm{g} / \mathrm{mL}\end{array}$ & $\begin{array}{c}\text { Non-toxic in Artemia } \\
\text { lethality assay }\end{array}$ & $\begin{array}{l}{[71]} \\
{[41]} \\
{[40]}\end{array}$ \\
\hline $\begin{array}{l}\text { Terminalia sambesiacia } \\
\text { Engl. \& Diels. }\end{array}$ & Not stated & $\begin{array}{c}\text { E. coli } \\
\text { P. aeruginosa } \\
\end{array}$ & $\begin{array}{l}\text { (A) } 60 \mu \mathrm{g} / \mathrm{mL} \\
\text { (A) } 60 \mu \mathrm{g} / \mathrm{mL} \\
\end{array}$ & Not determined & {$[79]$} \\
\hline
\end{tabular}


TABLE 2: Continued.

\begin{tabular}{|c|c|c|c|c|c|}
\hline Plant species & $\begin{array}{l}\text { Plant part } \\
\text { used }\end{array}$ & $\begin{array}{c}\text { Pathogens } \\
\text { screened }\end{array}$ & MIC values & Toxicity evaluation & References \\
\hline $\begin{array}{l}\text { Terminalia sericea Burch. ex } \\
\text { DC. }\end{array}$ & Leaves & $\begin{array}{l}\text { E. coli } \\
\text { K. pneumoniae } \\
\text { P. mirabilis } \\
\text { P. vulgaris } \\
\end{array}$ & $\begin{array}{l}\text { (M) } 396 \mu \mathrm{g} / \mathrm{mL} \text {; (W) } 276 \mu \mathrm{g} / \mathrm{mL} \\
\text { (M) } 254 \mu \mathrm{g} / \mathrm{mL} \text {; (W) } 318 \mu \mathrm{g} / \mathrm{mL} \\
\text { (M) } 417 \mu \mathrm{g} / \mathrm{mL} \text {; (W) } 103 \mu \mathrm{g} / \mathrm{mL} \\
\text { (M) } 508 \mu \mathrm{g} / \mathrm{mL} \text { (W) } 520 \mu \mathrm{g} / \mathrm{mL}\end{array}$ & $\begin{array}{l}\text { Non-toxic in Artemia } \\
\text { lethality assay }\end{array}$ & $\begin{array}{l}{[71]} \\
{[41]} \\
{[40]}\end{array}$ \\
\hline Trichilia dregeana Sond. & Leaves & $\begin{array}{l}\text { E. coli } \\
\text { E. faecalis }\end{array}$ & $\begin{array}{c}\text { (M) } 1000 \mu \mathrm{g} / \mathrm{mL} ;(\mathrm{W})>8000 \mu \mathrm{g} / \mathrm{mL} \text {; } \\
\text { (D) } 8000 \mu \mathrm{g} / \mathrm{mL} \\
\text { (M) } 1500 \mu \mathrm{g} / \mathrm{mL} ;(\mathrm{W})>8000 \mu \mathrm{g} / \mathrm{mL} ; \\
\text { (D) } 4000 \mu \mathrm{g} / \mathrm{mL}\end{array}$ & $\begin{array}{l}\text { Non-toxic in Artemia } \\
\text { lethality assay }\end{array}$ & {$[80]$} \\
\hline Trichilia emetica Vahl. & Leaves & E. coli & $\begin{array}{c}\text { (M) } 1000 \mu \mathrm{g} / \mathrm{mL} ;(\mathrm{W})>8000 \mu \mathrm{g} / \mathrm{mL} \\
\text { (D) } 8000 \mu \mathrm{g} / \mathrm{mL}\end{array}$ & $\begin{array}{c}\text { Non-toxic in Artemia } \\
\text { lethality assay }\end{array}$ & {$[80,84]$} \\
\hline Tulbaghia violaceae Harv. & Leaves & $\begin{array}{l}\text { E. coli } \\
\text { K. pneumoniae } \\
\text { P. mirabilis }\end{array}$ & $\begin{array}{c}\text { Roots: (M) } 387 \mu \mathrm{g} / \mathrm{mL} \text {; Leaves: (M) } \\
30 \mu \mathrm{g} / \mathrm{mL} \\
\text { Roots; (M) } 526 \mu \mathrm{g} / \mathrm{mL} \text {; (W) } 613 \mu \mathrm{g} / \mathrm{mL} \\
\text { Leaves: (W) } 125 \mu \mathrm{g} / \mathrm{mL} \\
\end{array}$ & $\begin{array}{l}\mathrm{LC}_{50}=772 \mu \mathrm{g} / \mathrm{mL} \text { in } \\
\text { Artemia lethality assay }\end{array}$ & $\begin{array}{l}{[71]} \\
{[41]} \\
{[40]}\end{array}$ \\
\hline Turraea floribunda Hochst. & Leaves & E. coli & $\begin{array}{c}\text { (M) } 4000 \mu \mathrm{g} / \mathrm{mL} ;(\mathrm{W})>8000 \mu \mathrm{g} / \mathrm{mL} \\
\text { (D) } 4000 \mu \mathrm{g} / \mathrm{mL}\end{array}$ & $\begin{array}{l}\text { Non-toxic in Artemia } \\
\text { lethality assay }\end{array}$ & {$[80]$} \\
\hline Turraea obtusifolia Hochst. & Leaves & E. coli & $\begin{array}{c}\text { (M) } 2000 \mu \mathrm{g} / \mathrm{mL} ;(\mathrm{W})>8000 \mu \mathrm{g} / \mathrm{mL} \text {; } \\
\text { (D) } 8000 \mu \mathrm{g} / \mathrm{mL}\end{array}$ & $\begin{array}{c}\text { Non-toxic in Artemia } \\
\text { lethality assay }\end{array}$ & {$[80]$} \\
\hline Vepris reflexa I. Verd. & Not stated & $\begin{array}{c}\text { E. coli } \\
\text { P. aeruginosa }\end{array}$ & $\begin{array}{l}\text { (A) } 600 \mu \mathrm{g} / \mathrm{mL} \\
\text { (A) } 1250 \mu \mathrm{g} / \mathrm{mL}\end{array}$ & Not determined & [79] \\
\hline \multirow[b]{2}{*}{$\begin{array}{l}\text { Warburgia salutaris } \\
\text { (Bertol.f.) Chiov. }\end{array}$} & \multirow[b]{2}{*}{$\begin{array}{l}\text { Leaves } \\
\text { and bark }\end{array}$} & $\begin{array}{c}\text { E. coli } \\
\text { K. pneumoniae }\end{array}$ & $\begin{array}{c}\text { Leaves: (M) } 239 \mu \mathrm{g} / \mathrm{mL} ;(\mathrm{W}) 304 \mu \mathrm{g} / \\
\mathrm{mL} \\
\begin{array}{c}\text { (b) } 624 \mu \mathrm{g} / \mathrm{mL} \text { (bark); (W) } 677 \mu \mathrm{g} / \mathrm{mL} \\
\text { (bark) }\end{array}\end{array}$ & \multirow[b]{2}{*}{$\begin{array}{l}\text { Non-toxic in Artemia } \\
\text { lethality assay }\end{array}$} & {$[41]$} \\
\hline & & P. mirabilis & $\begin{array}{c}\text { (M) } 623 \text { and } 465 \mu \mathrm{g} / \mathrm{mL} \text { (bark and } \\
\text { leaves respectively); (W) } 417 \mu \mathrm{g} / \mathrm{mL} \\
\text { (bark) } \\
\text { (M) } 450 \text { and } 688 \mu \mathrm{g} / \mathrm{mL} \text { (bark and } \\
\text { leaves respectively); (W) } 1203 \mu \mathrm{g} / \mathrm{mL} \\
\text { (leaves) }\end{array}$ & & {$[40]$} \\
\hline Ximenia caffra Sond. & Stem bark & E. coli & $\begin{array}{l}\text { (M) } 156 \mu \mathrm{g} / \mathrm{mL} \text {; (W) } 312 \mu \mathrm{g} / \mathrm{mL} \text {; (E) } \\
312 \mu \mathrm{g} / \mathrm{mL} \text {; (A) } 312 \mu \mathrm{g} / \mathrm{mL}\end{array}$ & Not determined & {$[82]$} \\
\hline $\begin{array}{l}\text { Zanthoxylem capensis } \\
\text { (Thunb.) Harv. }\end{array}$ & Not stated & $\begin{array}{c}\text { E. coli } \\
\text { P. aeruginosa }\end{array}$ & $\begin{array}{l}\text { (A) } 310 \mu \mathrm{g} / \mathrm{mL} \\
\text { (A) } 310 \mu \mathrm{g} / \mathrm{mL}\end{array}$ & Not determined & {$[76]$} \\
\hline Ziziphus murconata Willd. & Bark & $\begin{array}{c}\text { E. coli } \\
\text { P. aeruginosa }\end{array}$ & $\begin{array}{l}\text { (M) } 2500 \mu \mathrm{g} / \mathrm{mL} \\
\text { (M) } 1250 \mu \mathrm{g} / \mathrm{mL}\end{array}$ & Not determined & {$[75]$} \\
\hline
\end{tabular}

representation, with nineteen species reported as treatments for UTIs (Figure 1). Leguminosae were also commonly used as UTI therapies, with fourteen plant species reported [42, 43]. Asparagaceae, Rutaceae, and Lamiaceae were also well represented, with eight, six, and six species used to treat UTIs, respectively. Five species each of Amaryllidaceae, Solanaceae, and Malvaceae, as well as four species of both Euphorbiaceae and Poaceae, and three species of Geraniaceae and Xanthorrhoeaceae were also used for this purpose. A further twenty-four plant families were represented by two or fewer individual species. Of these, Aptosimum procumbens (Lehm.) Burch. ex Steud, Arctopus echinatus L., Boophone disticha (L.f.) Herb., Bowiea volubilis Harv., Cardiospermum halicacabum L., Cissampelos capensis L.f., Galenia africana L., Helichrysum odoratissimum (L.) Sweet, and Zantedeschia albomaculata (Hook.) Baill have been cited by several sources that also experimentally validated their use for the treatment of UTIs [47, 62, 64]. Approximately $47 \%$ of the plant species identified in our study were cited by multiple sources as traditional UTI therapies, indicating that screening and validation of those species should be prioritised.

The main plant parts used to prepare therapies to treat UTIs are leaves $(27 \%)$, followed by roots, bulbs, and rhizomes (22\%) (Figure 2). For 48 plant species (31\%), the specific plant part used was not specified in the cited literature. For Solanum capense L. and Pelargonium ramosissimum Willd., both leaves and stems were used to treat UTIs, so both parts are recorded in Table 1 for that purpose $[43,58]$. Fruits were found to be the least used parts as they are only available for short periods seasonally and may not be always readily available.

3.2. Dosage and Toxicity. Long term use of medicinal plants to treat diseases has resulted in the assumption that medicinal plants are nontoxic and safe for therapeutic use [39]. Of the plants specified for traditional use for UTIs (Table 1), 


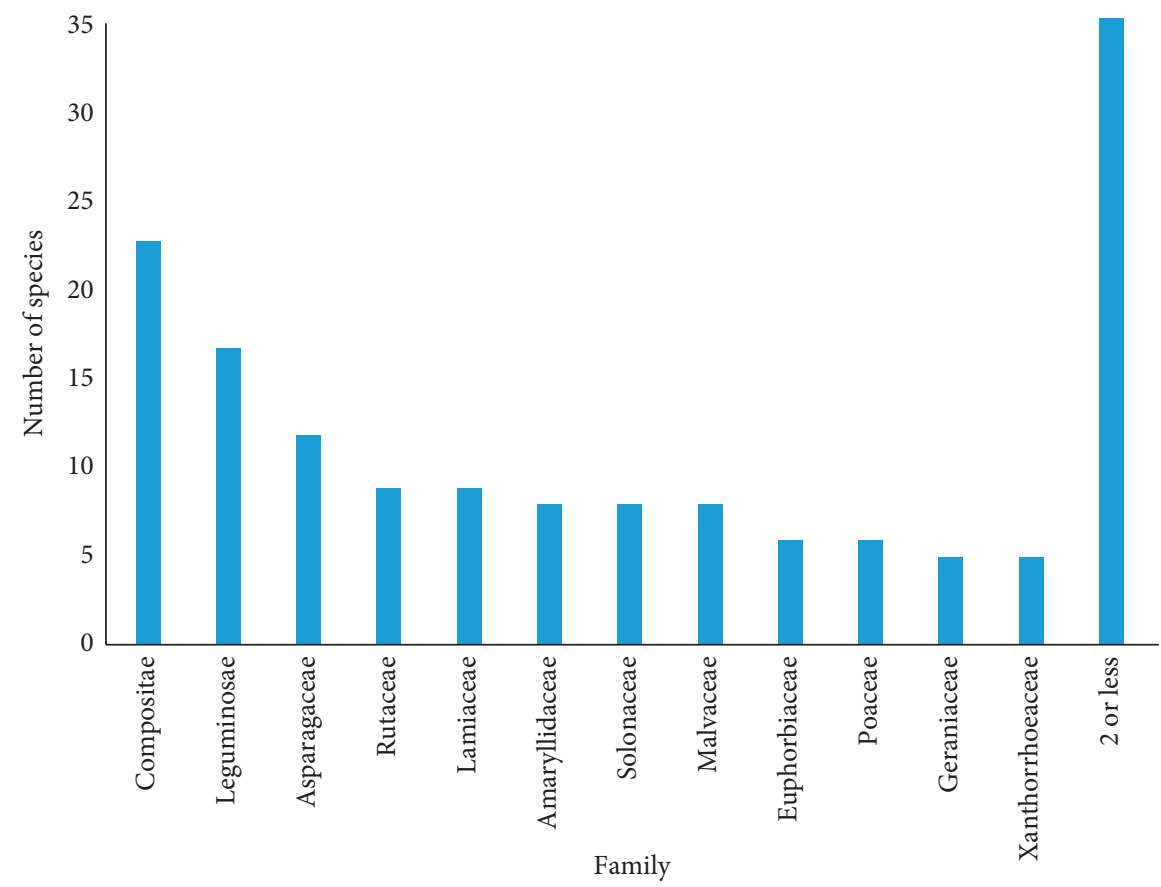

FIGURE 1: The number of species per plant family used to treat urinary tract infections. " 2 or less" indicates families where there were $\leq$ two plant species represented.

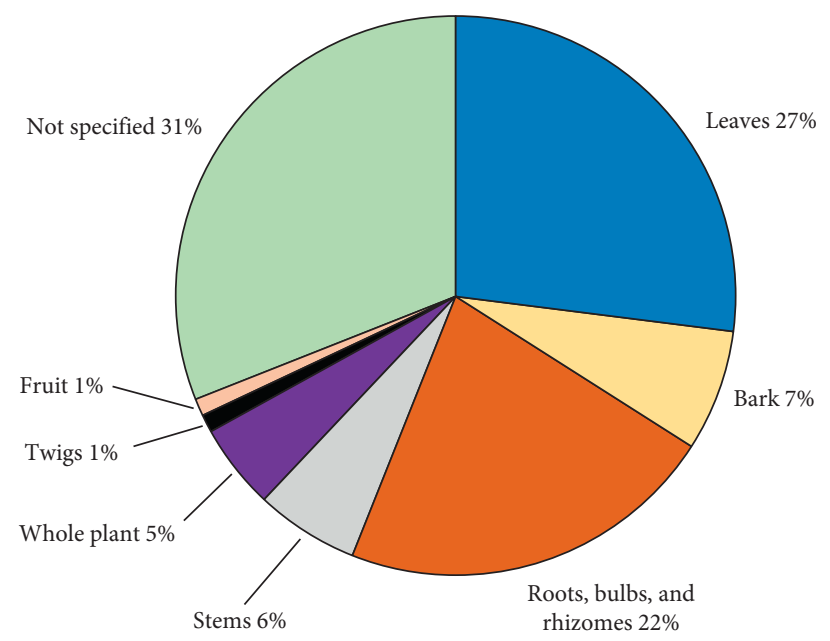

FIgURE 2: Frequency of use of different plant parts used to treat urinary tract infections in southern African traditional medicine.

none had their therapeutic dosage ranges recorded. It is noteworthy that several of these species have been reported to contain cardiac glycoside toxins (for example, Bowiea volubilis and Acokanthera oppositifolia) $[70,85,86]$ and cucurbitacin (widely distributed in the Cucurbitaceae, Rubiaceae, Euphorbiaceae, and Cruciferae families), which have several adverse effects and toxicities [87]. Thus, further studies into the pharmacological and safety profiles of the majority of the plants listed in Table 1 are required to determine their safety for the treatment of UTIs. Indeed, a common trend noted was that information on dosage and toxicity is lacking, not only for the treatment of UTIs, but in the records listing South African plant use against many other diseases.
3.3. Scientific Studies on the Effects of Southern African Plants against Urinary Tract Infections. In a review of South African plants that have been studied for their antimicrobial properties, it was concluded that, before 2017, there had been no specific uropathogenic studies focusing on the antimicrobial activities of southern African medicinal plants [35]; however, pathogens such as E. coli were included in other screening studies. For example, E. coli is also associated with gastrointestinal diseases, and some strains of this pathogen cause diarrhoea [88]. It is therefore not surprising that studies screening South African plants against E. coli more frequently focus on its involvement in those diseases [73, 77, 82]. Escherichia coli is also a widely studied bacterium and is often included in studies performing screening 
against generic bacterial panels. Whilst these studies do not focus on the involvement of E. coli in UTIs, they have still been reported in this study as they demonstrate inhibitory activity against this bacterium, regardless of infection site. Similarly, P. mirabilis and K. pneumoniae are also associated with other diseases, including the autoimmune diseases, rheumatoid arthritis, and ankylosing spondylitis, respectively [40,41]. Furthermore, Pseudomonas aeruginosa not only causes UTIs, but also has been associated with several other diseases [89]. Studies that screened southern African plant extracts for these bacteria were also included, regardless of the disease state that was the focus of the study.

A total of 85 plants used in southern African traditional medicine to treat UTIs have been tested for inhibitory activity against at least one UTI-causing bacterium. Not surprisingly, the inhibitory properties of southern African traditional medicine plants against $E$. coli were particularly well studied. Indeed, 82 species (96\% of the total plant species screened) have previously been reported to inhibit $E$. coli growth at a noteworthy concentration. Notably, the majority of the plant species that have been screened against E. coli have also been screened against one or more other UTI-causing bacteria. Screening of southern African plants against $P$. aeruginosa has also received substantial attention, with 36 southern African plants reported to have noteworthy activity against this species. This is important as $P$. aeruginosa is resistant to many conventional antibiotics. Therefore, plant species with activity against this bacterium may be particularly promising, not only against UTIs, but also against other diseases in which $P$. aeruginosa causes pathogenesis, including multiple sclerosis [89] and cystic fibrosis [84]. Particularly, good $P$. aeruginosa inhibitory activity was reported for two Terminalia spp. (T. phanerophlebia and T. sambesiaca), with MICs of 80 and $60 \mu \mathrm{g} / \mathrm{mL}$, respectively [79]. Proteus spp. and K. pneumoniae were each screened against 14 southern African plant species. Nearly all of the plants screened against those bacteria were tested in two separate studies that used the same panels of plant species [40,41]. Both of those studies screened a larger panel of South African medicinal plants than listed here, and only those plant species with appreciable activity are reported herein. Notably, we were only able to find reports of S. saprophyticus inhibitory activity for two closely related South African plants of the genus Alchornea (A. cordifolia and A. laxiflora) [74]. As this bacterium is responsible for approximately $6 \%$ of uncomplicated UTIs, screening of South African plants for this bacterium is a priority for future studies.

Notably, 46 of the bacterial screening studies reported herein did not test toxicity within the same study, and it is therefore not possible to determine therapeutic indexes. Therefore, whilst the plant species examined in those studies may have noteworthy antibacterial activity, it is not possible to comment on their safety and therefore their potential as therapies to treat UTIs. Of the plants that were screened for toxicity alongside antibacterial activity, $\mathrm{LC}_{50}$ values that indicate a lack of toxicity were reported for 28 plant species. Of concern, 11 plant species (A. laxiflora, Bolusanthus speciosus, Calpurnia aurea, Cremaspora triflora, E. croceum,
Heteromorpha arborescens, Hypericum roeperianum, Maesa lanceolata, Morus mesozygia, Pittosporum viridiflorum, and Tulbaghia violacea) were reported to have appreciable toxicity, and therefore caution is recommended for their use. Of particular concern, $\mathrm{LC}_{50}$ values of $2-14 \mu \mathrm{g} / \mathrm{mL}$ were reported for C. triflora, E. croceum, and M. lanceolata. Given the MIC values of these plant species against E. coli, the therapeutic indexes (as low as 0.008) can be calculated, indicating that these extracts are extremely unsafe for therapeutic use as the extracts are toxic at $\sim 1 \%$ of the concentration required to achieve the therapeutic effect. However, it is noteworthy that all of these low $\mathrm{LC}_{50}$ values in Vero cells were determined in a single study [77]. That study also reported low $\mathrm{LC}_{50}$ values (lower than $100 \mu \mathrm{g} / \mathrm{mL}$ ) for every plant species that was tested in that study, and therefore the results may be an anomaly of that study. The toxicity of these plant species needs to be verified in future studies to evaluate their safety for therapeutic use.

\section{Discussion and Conclusion}

Urinary tract infections are one of the most widespread classes of infectious diseases globally, yet the development of new therapies to treat these infections remains relatively neglected. Whilst UTIs cause discomfort, they rarely cause mortality or serious morbidity except in immune-compromised individuals. It is likely that the relative lack of severity of these infections may contribute to the low number of studies into the effects of southern African plants specifically targeted at bacteria that cause these infections. Indeed, most of these studies have occurred in the most recent 15-year period. Interestingly, the increase in research in this field coincides with increases in the incidence of antibiotic resistance. Several studies have already screened some South African plants for the ability to inhibit UTIcausing bacteria. Indeed, Table 2 summarises studies screening 85 plant species against UTI-causative bacteria.

Surprisingly, despite 153 plant species identified with documented uses to treat UTIs, only 85 species have been reported to have noteworthy inhibitory activity against the main UTI-causative bacteria species. Furthermore, most of the tested plants were not selected for screening based on their traditional use to treat UTIs. Instead, in many cases, the plant species were screened against the bacteria based on their involvement in other diseases. Escherichia coli is a common gastrointestinal bacterium, and several studies screened plant extracts against this bacterium to examine its potential to treat diarrhoea. The studies described in this review focussed on the main bacterial species that can cause UTIs (E. coli, K. pneumoniae, P. aeruginosa, P. mirabilis, and $S$. saprophyticus). Combined, these bacteria account for $>90 \%$ of the cases of uncomplicated UTIs, highlighting their importance to those studies [11]. However, for these pathogens, we were only able to locate a single study that tested South African plants against S. saprophyticus [74], and future studies screening plants against this bacterium are required. Furthermore, other bacterial species are also responsible for a significant proportion of UTIs. In particular, unspecified Enterococcus spp. account for approximately 6\% 
and $11 \%$ of uncomplicated and complicated UTIs, respectively [11], and therefore future studies screening South African plants against these pathogens are warranted. Furthermore, our review focussed on the bacterial causes of UTIs as they account for nearly all reported cases. However, C. albicans, as well as some viruses and protozoa, may also cause UTIs and should not be neglected in future studies. Further studies are required to screen those species against the other major causes of UTIs. Additionally, all the previous studies have screened plant species against UTI-causative bacteria that are susceptible to conventional antibiotic therapies. To date, screening plants against antibiotic-resistant bacterial strains has been largely neglected. As there have been substantial increases in the prevalence of antibiotic-resistant bacterial pathogens in recent years, it is important that the plants identified herein are also screened against resistant bacterial strains to further evaluate the potential in clinical environments. Furthermore, when examining antimicrobial efficacy, it must be noted that UTIs are very often biofilm-borne, and this aspect has been neglected in the screening. Only one study [78] focussed on 14 plant species utilising bacterial communication systems via antiquorum sensing signalling and in biofilm studies. Clearly, this area remains untapped, and there is a possibility for plant species to not only act on planktonic bacterial cells, but also inhibit or prevent biofilm formation.

It appears that plant species selection for several studies was based more on plant availability rather than ethnobotanical use. Another aspect of the previous studies is that the plant part tested does not always correlate with the part traditionally used. It is likely that availability may also have been a significant factor in selection of plant part in those studies. However, the chemistry may differ substantially between different plant parts, and they may therefore induce completely different biological activities. Where possible, screening and evaluation studies should test the plant part used traditionally, as well as an approximation of how it was processed for use. These factors may have significant impacts on the toxicity of the preparation. Future studies testing an approximation of the traditional plant preparations are therefore required to validate the traditional use of these plants to treat UTIs.

To be useful in the treatment of UTIs, an extract (or purified compound derived from an extract) must have relatively low toxicity. This is particularly true for the treatment of recurrent infections. Surprisingly, many of the plant species screened for inhibitory activity against UTIcausative bacteria were not tested for toxicity in the same studies. This may be because many of these plants have been used in traditional healing systems for hundreds of years without reported toxicity and are therefore assumed to be safe. However, some plant species are prepared by different methods to test bioactivity from the preparation method used by traditional medicine practitioners. Different preparation methods may dramatically alter the phytochemical composition of different preparations and therefore may also affect their toxicity profiles. Indeed, several studies reported toxic, carcinogenic, and mutagenic effects for extracts prepared from plants traditionally used as medicines
[33]. Several of the studies highlighted in this review have also investigated the toxicity of southern African plant species traditionally used to treat UTIs $[40,41,71,73,77,80]$. Whilst most of those studies reported that the plant extracts were nontoxic, one study reported very low $\mathrm{LC}_{50}$ values against Vero cells for several plant species, indicating that those species may not be safe to use medicinally. However, the results of that study may be erroneous as all the plant species tested had low $\mathrm{LC}_{50}$, and verification of these results is required. Of further note, several different toxicity assays (human cell lines, Vero monkey kidney cells, Artemia nauplii assays) were used to screen the plant species in different studies, making comparisons difficult between studies. Ideally, toxicity studies should incorporate more than one toxicity assay to allow for better comparisons between studies.

Ethnobotanical records have already identified several promising plant species used in traditional South African medicinal systems to treat UTIs, and several of those species (as well as multiple species for which a traditional use against UTIs was not recorded) have already been tested against one or more UTI-causative bacteria. Further research is required to screen all identified species against each of the UTIcausative bacteria (rather than just one or two of them) and against antibiotic-resistant bacterial strains that are becoming increasingly common. Additionally, all previous studies have tested the plant extracts in vitro. As considerably different effects may be seen in vivo due to bioavailability differences, studies in animal models are also required.

Overall, there is evidence that southern African medicinal plants have potential to treat UTIs and, with further in-depth analysis, could be the new alternative to cranberry juice which is internationally recognised as a safe natural alternative for treating infections of the urinary tract.

\section{Data Availability}

All data are included within this study and are also available from the corresponding author on request.

\section{Conflicts of Interest}

The authors declare no conflicts of interest.

\section{Acknowledgments}

The authors are thankful for the financial support provided by the Department of Pharmacy and Pharmacology, University of the Witwatersrand, South Africa, and by the Environmental Futures Research Institute, Griffith University, Australia.

\section{References}

[1] M. Medina and E. Castillo-Pino, "An introduction to the epidemiology and burden of urinary tract infections," Therapeutic Advances in Urology, vol. 11, Article ID $1756287219832172,2019$. 
[2] A. L. Flores-Mireles, J. N. Walker, M. Caparon, and S. J. Hultgren, "Urinary tract infections: epidemiology, mechanisms of infection and treatment options," Nature Reviews Microbiology, vol. 13, no. 5, pp. 269-284, 2015.

[3] O. Storme, J. Tirán Saucedo, A. Garcia-Mora, M. DehesaDávila, and K. G. Naber, "Risk factors and predisposing conditions for urinary tract infection," Therapeutic Advances in Urology, vol. 11, Article ID 1756287218814382, 2019.

[4] C. M. Chu and J. L. Lowder, "Diagnosis and treatment of urinary tract infections across age groups," American Journal of Obstetrics and Gynecology, vol. 219, pp. 40-51, 2018.

[5] B. Foxman, "Epidemiology of urinary tract infections: incidence, morbidity, and economic costs," American Journal of Medicine, vol. 113, pp. 5S-11S, 2002.

[6] M. Cek, Z. Tandoğdu, F. Wagenlehner, P. Tenke, K. Naber, and T. E. Bjerklund-Johansen, "Healthcare-associated urinary tract infections in hospitalized urological patients-a global perspective: results from the GPIU studies 2003-2010," World Journal of Urology, vol. 32, no. 6, pp. 1587-1594, 2014.

[7] H. S. Choe, S. J. Lee, Y. H. Cho et al., "Aspects of urinary tract infections and antimicrobial resistance in hospitalized urology patients in Asia: 10-year results of the Global Prevalence Study of Infections in Urology (GPIU)," Journal of Infection and Chemotherapy: Official Journal of the Japan Society of Chemotherapy, vol. 24, pp. 278-283, 2018.

[8] R. Ebana, U. Edet, U. Ekanemesang, C. Etok, G. Ikon, and M. Noble, "Phytochemical screening and antimicrobial activity of three medicinal plants against urinary tract infection pathogens," Asian Journal of Medicine and Health, vol. 1, no. 2, pp. 1-7, 2016.

[9] T. E. B. Johansen, H. Botto, M. Cek et al., "Critical review of current definitions of urinary tract infections and proposal of an EAU/ESIU classification system," International Journal of Antimicrobial Agents, vol. 38, pp. 64-70, 2011.

[10] C. W. Tan and M. P. Chlebicki, "Urinary tract infections in adults," Singapore Medical Journal, vol. 57, no. 9, pp. 485-490, 2016.

[11] I. E. Cock and S. F. Van Vuuren, "A review of the traditional use of southern African medicinal plants for the treatment of fungal skin infections," Journal of Ethnopharmacology, vol. 251, Article ID 112539, 2020.

[12] A. Zida, S. Bamba, A. Yacouba, R. Ouedraogo-Traore, and R. T. Guiguemdé, "Anti- Candida albicans natural products, sources of new antifungal drugs: a review," Journal de Mycologie Médicale, vol. 27, no. 1, pp. 1-19, 2017.

[13] P. Vikrant, J. Priya, and K. B. Nirichan, "Plants with antiCandida activity and their mechanism of action: a review," Journal of Environmental Research and Development, vol. 9, no. 4, p. 1189, 2015.

[14] S. Salvatore, S. Salvatore, E. Cattoni et al., "Urinary tract infections in women," European Journal of Obstetrics \& Gynecology and Reproductive Biology, vol. 156, no. 2, pp. 131-136, 2011.

[15] M. J. Cheesman, A. Ilanko, B. Blonk, and I. E. Cock, "Developing new antimicrobial therapies: are synergistic combinations of plant extracts/compounds with conventional antibiotics the solution?" Pharmacognosy Reviews, vol. 11, no. 22, pp. 57-72, 2017.

[16] B. Foxman, B. Gillespie, J. Koopman et al., "Risk factors for second urinary tract infection among college women," American Journal of Epidemiology, vol. 151, no. 12, pp. 1194-1205, 2000.

[17] A. R. Brumbaugh and H. L. Mobley, "Preventing urinary tract infection: progress toward an effective Escherichia colivaccine," Expert Review of Vaccines, vol. 11, no. 6, pp. 663-676, 2012.

[18] B. Foxman and M. Buxton, "Alternative approaches to conventional treatment of acute uncomplicated urinary tract infection in women," Current Infectious Disease Reports, vol. 15, no. 2, pp. 124-129, 2013.

[19] S. Meier, R. Weber, R. Zbinden, C. Ruef, and B. Hasse, "Extended-spectrum $\beta$-lactamase-producing Gram-negative pathogens in community-acquired urinary tract infections: an increasing challenge for antimicrobial therapy," Infection, vol. 39, no. 4, pp. 333-340, 2011.

[20] J. Fennell, A. Vellinga, B. Hanahoe et al., "Increasing prevalence of ESBL production among Irish clinical Enterobacteriaceae from 2004 to 2008: an observational study," BMC Infectious Diseases, vol. 12, no. 116, 2012.

[21] L. Dethlefsen, S. Huse, M. L. Sogin, and D. A. Relman, "The pervasive effects of an antibiotic on the human gut microbiota, as revealed by deep $16 \mathrm{~S}$ rRNA sequencing," PLoS Biology, vol. 6, Article ID e280, 2008.

[22] B. W. Trautner and K. Gupta K, "The advantages of second best: comment on "Lactobacilli vs antibiotics to prevent urinary tract infections", "Archives of Internal Medicine, vol. 172, pp. 712-714, 2012.

[23] A. Baerheim, "Empirical treatment of uncomplicated cystitis," Scandinavian Journal of Primary Health Care, vol. 30, no. 1, pp. 1-2, 2012.

[24] World Health Organization, WHO Traditional Medicine Strategy: 2014-2023, World Health Organization, Geneva, Switzerland, 2013, https://www.who.int/medicines/ publications/traditional/trm_strategy14_23/en/.

[25] R. A. Street and G. Prinsloo, "Commercially important medicinal plants of South Africa: a review," Journal of Chemistry, vol. 2013, Article ID 205048, 16 pages, 2013.

[26] A. P. Dold and M. L. Cocks, "The trade in medicinal plants in the Eastern Cape province, South Africa," South African Journal of Science, vol. 98, pp. 589-597, 2002.

[27] M. Mander and G. Breton, "Overview of the medicinal plants industry in Southern Africa," in Commercialising Medicinal Plants-A Southern African Guide, N. Diederichs, Ed., Sun Press, Stellenbosch, South Africa, 2006.

[28] M. Mander and M. McKenzie, Southern African Trade Directory of Indigenous Natural Products, Commercial Products from the Wild Group, Stellenbosch, South Africa, 2005.

[29] S. M. K. Rates, "Plants as source of drugs," Toxicon, vol. 39, no. 5, pp. 603-613, 2001.

[30] P. Sheriffs, "Truths and tradition," Femina, vol. 113, pp. 62-65, 1996.

[31] J. De Jong, Traditional Medicine in Sub-saharan Africa: Its Importance and Potential Policy Options, Report for World Bank, Washington, DC, USA, 1991.

[32] M. Boukandou Mounanga, L. Mewono, and S. Aboughe Angone, "Toxicity studies of medicinal plants used in subSaharan Africa," Journal of Ethnopharmacology, vol. 174, pp. 618-627, 2015.

[33] C. W. Fennell, K. L. Lindsey, L. J. McGaw et al., "Assessing African medicinal plants for efficacy and safety: pharmacological screening and toxicology," Journal of Ethnopharmacology, vol. 94, no. 2-3, pp. 205-217, 2004.

[34] G. Bodeker, "Medicinal; plant biodiversity and local healthcare-sustainable use and livelihood development," in Proceedings of the 17th Commonwealth Forestry Conference, Forestry Commission, Colombo, Sri Lanka, March 2005.

[35] S. Van Vuuren and D. Holl, "Antimicrobial natural product research: a review from a South African perspective for the 
years 2009-2016," Journal of Ethnopharmacology, vol. 208, pp. 236-252, 2017.

[36] S. F. van Vuuren, M. N. Nkwanyana, and H. de Wet, "Antimicrobial evaluation of plants used for the treatment of diarrhoea in a rural community in northern Maputaland, KwaZulu-Natal, South Africa," BMC Complementary and Alternative Medicine, vol. 15, no. 1, pp. 1-8, 2015.

[37] H. de Wet, M. N. Nkwanyana, and S. F. van Vuuren, "Medicinal plants used for the treatment of diarrhoea in Northern Maputaland, KwaZulu-Natal Province, South Africa," Journal of Ethnopharmacology, vol. 130, no. 2, pp. 284-289, 2010.

[38] A. Orchard and S. van Vuuren, "Commercial essential oils as potential antimicrobials to treat skin diseases," Evidence-based Complementary and Alternative Medicine, vol. 2017, Article ID 4517971, 92 pages, 2017.

[39] U. Mabona and S. F. Van Vuuren, "Southern African medicinal plants used to treat skin diseases," South African Journal of Botany, vol. 87, pp. 175-193, 2013.

[40] I. E. Cock and S. F. Van Vuuren, "Anti-proteus activity of some South African medicinal plants: their potential for the prevention of rheumatoid arthritis," Inflammopharmacology, vol. 22, no. 1, pp. 23-36, 2014

[41] I. E. Cock and S. F. Van Vuuren, "The potential of selected South African plants with anti-Klebsiella activity for the treatment and prevention of ankylosing spondylitis," Inflammopharmacology, vol. 23, no. 1, pp. 21-35, 2015.

[42] J. M. Watt and M. G. Breyer-Brandwijk, The Medicinal and Poisonous Plants of Southern and Eastern Africa Being an Account of Their Medicinal and Other Uses, Chemical Composition, Pharmacological Effects and Toxicology in Man and Animal, Livingstone Publishing, Edinburgh, UK, 1962.

[43] A. Hutchings, A. H. Scott, G. Lewis, and A. B. Cunningham, Zulu Medicinal Plants: An Inventory, University of Natal Press, Pietermaritzburg, South Africa, 1996.

[44] B. E. Van Wyk, B. van Oudtshoorn, and N. Gericke, Medicinal Plants of South Africa, Briza Publications, Pretoria, South Africa, 2nd edition, 2009.

[45] B.-E. Van Wyk and B. Gorelik, "The history and ethnobotany of Cape herbal teas," South African Journal of Botany, vol. 110, pp. 18-38, 2017.

[46] E. Von Koenen, Medicinal, Poisonous, and Edible Plants in Namibia, Klaus Hess Publishers, Windhoek, Namibia, 2001.

[47] L. S. Mhlongo and B.-E. Van Wyk, "Zulu medicinal ethnobotany: new records from the Amandawe area of KwaZuluNatal, South Africa," South African Journal of Botany, vol. 122, pp. 266-290, 2019.

[48] L. Aston Philander, "An ethnobotany of Western Cape Rasta bush medicine," Journal of Ethnopharmacology, vol. 138, no. 2, pp. 578-594, 2011.

[49] T. S. A. Thring and F. M. Weitz, "Medicinal plant use in the bredasdorp/elim region of the southern overberg in the Western Cape province of South Africa," Journal of Ethnopharmacology, vol. 103, no. 2, pp. 261-275, 2006.

[50] I. M. Hulley and B. -E. Van Wyk, "Quantitative medicinal ethnobotany of Kannaland (Western Little Karoo, South Africa): non-homogeneity amongst villages," South African Journal of Botany, vol. 122, pp. 225-265, 2017.

[51] J. J. J. De Beer and B.-E. Van Wyk, "An ethnobotanical survey of the Agter-Hantam, Northern Cape province, South Africa," South African Journal of Botany, vol. 77, no. 3, pp. 741-754, 2011.

[52] H. De Wet and B.-E. Van Wyk, "An ethnobotanical survey of southern African Menispermaceae," South African Journal of Botany, vol. 74, no. 1, pp. 2-9, 2008.
[53] H. Kling, Die Sieketrooster, Van de Sandt de Villiers, Cape Town, South Africa, 1923.

[54] E. B. Maliehe, Medicinal Plants and Herbs of Lesotho, Mafeteng Development Project, Maseru, Lesotho, 1997.

[55] R. B. Mulaudzi, A. R. Ndhlala, and J. Van Staden, "Ethnopharmacological evaluation of a traditional herbal remedy used to treat gonorrhoea in Limpopo province, South Africa," South African Journal of Botany, vol. 97, pp. 117-122, 2015.

[56] J. M. Nortje and B.-E. Van Wyk, "Medicinal plants of the Kamiesberg, Namaqualand, South Africa," Journal of Ethnopharmacology, vol. 171, pp. 205-222, 2015.

[57] B.-E. Van Wyk, H. de Wet, and F. R. Van Heerden, "An ethnobotanical survey of medicinal plants in the southeastern Karoo, South Africa," South African Journal of Botany, vol. 74, no. 4, pp. 696-704, 2008.

[58] A. T. Bryant, "Zulu medicine and medicine-men," Southern African Humanities, vol. 2, no. 1, pp. 1-3, 1909.

[59] F. Gebashe, M. Moyo, A. O. Aremu, J. F. Finnie, and J. Van Staden, "Ethnobotanical survey and antibacterial screening of medicinal grasses in KwaZulu-Natal Province, South Africa," South African Journal of Botany, vol. 122, pp. 467-474, 2019.

[60] F. Gebashe, A. O. Aremu, J. F. Finnie, and J. Van Staden, "Grasses in South African traditional medicine: a review of their biological activities and phytochemical content," South African Journal of Botany, vol. 122, pp. 301-329, 2019.

[61] M. A. Ngwenya, A. Koopman, and R. Williams, Ulwazi lwamaZulu Ngezimila: Isingeniso (Zulu Botanical Knowledge: An Introduction, National Botanical Institute (NBI), Durban, South Africa, 2003.

[62] A. Moteetee and B. E. Van Wyk, "The medical ethnobotany of Lesotho: a review," Bothalia, vol. 41, no. 1, pp. 209-228, 2011.

[63] A. Moteetee, R. O. Moffett, and L. Seleteng-Kose, "A review of the ethnobotany of the basotho of Lesotho and the free state province of South Africa (South Sotho)," South African Journal of Botany, vol. 122, pp. 21-56, 2019.

[64] R. Moffett, Sesotho Plant and Animal Names and Plants Used by the Basotho, Sunpress, Bloemfontein, South Africa, 1st edition, 2010.

[65] E. Pooley, Trees of Natal, Zululand and the Transkei, Natal Flora Publications Trust, Durban, South Africa, 1993.

[66] M. M. P. Mogale, D. C. Raimondo, and B.-E. VanWyk, "The ethnobotany of central Sekhukhuneland, South Africa," South African Journal of Botany, vol. 122, pp. 90-119, 2019.

[67] J. Gerstner, "A preliminary checklist of Zulu names of plants with short note," Bantu Studies, vol. 13, no. 2, pp. 131-150, 1939.

[68] G. Scott, E. P. Springfield, and N. Coldrey, "A pharmacognostical study of 26 South African plant species used as traditional medicines," Pharmaceutical Biology, vol. 42, no. 3, pp. 186-213, 2004.

[69] F. H. Ferreira, The Trees and Shrubs of South Africa 2, Ferreira (Roneod), Pretoria, South Africa, 1952.

[70] J. F. Finnie, F. E. Drewes, and J. Van Staden, "Bowiea volubilis Harv. ex hook.f. (sea onion): in vitro culture and the production of cardiac glycosides," in Medicinal and Aromatic Plants VII, pp. 84-97, Springer, Berlin, Germany, 1994.

[71] I. E. Cock and S. F. Van Vuuren, "South African food and medicinal plant extracts as potential antimicrobial food agents," Journal of Food Science and Technology, vol. 52, no. 11, pp. 6879-6899, 2015.

[72] I. M. S. Eldeen, E. E. Elgorashi, and J. Van Staden, "Antibacterial, anti-inflammatory, anti-cholinesterase and mutagenic effects of extracts obtained from some trees used in 
South African traditional medicine," Journal of Ethnopharmacology, vol. 102, no. 3, pp. 457-464, 2005.

[73] Z. Hübsch, R. L. Van Zyl, I. E. Cock, and S. F. Van Vuuren, "Interactive antimicrobial and toxicity profiles of conventional antimicrobials with Southern African medicinal plants," South African Journal of Botany, vol. 93, pp. 185-197, 2014.

[74] X. Siwe-Noundou, D. T. Ndinteh, D. K. Olivier et al., "Biological activity of plant extracts and isolated compounds from Alchornea laxiflora: anti-HIV, antibacterial and cytotoxicity evaluation," South African Journal of Botany, vol. 122, pp. 498-503, 2019.

[75] D. Luseba, E. E. Elgorashi, D. T. Ntloedibe, and J. Van Staden, "Antibacterial, anti-inflammatory and mutagenic effects of some medicinal plants used in South Africa for the treatment of wounds and retained placenta in livestock," South African Journal of Botany, vol. 73, no. 3, pp. 378-383, 2007.

[76] M. Adamu, V. Naidoo, and J. N. Eloff, "The antibacterial activity, antioxidant activity and selectivity index of leaf extracts of thirteen South African tree species used in ethnoveterinary medicine to treat helminth infections," $B M C$ Veterinary Research, vol. 10, no. 1, pp. 52-57, 2014.

[77] I. L. Elisha, F. S. Botha, L. J. McGaw, and J. N. Eloff, “The antibacterial activity of extracts of nine plant species with good activity against Escherichia coli against five other bacteria and cytotoxicity of extracts," BMC Complementary and Alternative Medicine, vol. 17, no. 1, pp. 133-210, 2017.

[78] I. T. Baloyi, S. Cosa, S. Combrinck, C. M. Leonard, and A. M. Viljoen, "Anti-quorum sensing and antimicrobial activities of South African medicinal plants against uropathogens," South African Journal of Botany, vol. 122, pp. 484-491, 2019.

[79] L. J. Shai, L. J. McGaw, P. Masoko, and J. N. Eloff, “Antifungal and antibacterial activity of seven traditionally used South African plant species active against Candida albicans," South African Journal of Botany, vol. 74, no. 4, pp. 677-684, 2008.

[80] M. O. Oyedeji-Amusa, S. Van Vuuren, and B. E. Van Wyk, "Antimicrobial activity and toxicity of extracts from the bark and leaves of South African indigenous Meliaceae against selected pathogens," South African Journal of Botany, vol. 133, pp. 83-90, 2020.

[81] B. A. Nkala, H. P. Mbongwa, and T. Qwebani-Ogunleye, "The in vitro evaluation of some South African plant extracts for minimum inhibition concentration and minimum bactericidal concentration against selected bacterial strains," International Journal of Scientific and Research Publications, vol. 9, no. 7, pp. 996-1004, 2019.

[82] M. C. Mathabe, R. V. Nikolova, N. Lall, and N. Z. Nyazema, "Antibacterial activities of medicinal plants used for the treatment of diarrhoea in Limpopo province, South Africa," Journal of Ethnopharmacology, vol. 105, no. 1-2, pp. 286-293, 2006.

[83] B. Kebede and W. Shibeshi, "Evaluation of in-vitro antibacterial and antifungal activities of crude extracts and solvent fractions of methanol extract of leaves of Ricinus communis Linn (Euphorbiaceae) against selected pathogens," Research Square, 2020.

[84] S. Malhotra, D. Hayes, and D. J. Wozniak, "Cystic fibrosis and Pseudomonas aeruginosa: the host-microbe interface," Clinical Microbiology Reviews, vol. 32, no. 3, 2019.

[85] A. O. Aremu, M. Moyo, S. O. Amoo, and J. Van Staden, "Ethnobotany, therapeutic value, phytochemistry and conservation status of Bowiea volubilis: a widely used bulbous plant in Southern Africa," Journal of Ethnopharmacology, vol. 174, pp. 308-316, 2015.

[86] S. Chaurasia and P. Sharma, "Evaluation of antibacterial and antimutagenic potential of Acokanthera oppositifolia and Leucaena leucocephala," American Journal of Pharmacy and Health Research, vol. 3, no. 1, pp. 246-258, 2015.

[87] A. Ponsankar, K. Sahayaraj, S. Senthil-Nathan et al., "Toxicity and developmental effect of cucurbitacin E from Citrullus colocynthis L. (Cucurbitales: Cucurbitaceae) against Spodoptera litura Fab. and a non-target earthworm Eisenia fetida Savigny," Environmental Science and Pollution Research, vol. 27, no. 19, pp. 23390-23401, 2020.

[88] I. A. Khalil, C. Troeger, B. F. Blacker et al., "Morbidity and mortality due to shigella and enterotoxigenic Escherichia coli diarrhoea: the global burden of disease study 1990-2016," The Lancet Infectious Diseases, vol. 18, no. 11, pp. 1229-1240, 2018.

[89] I. E. Cock and M. Cheesman, "The potential of plants of the genus Syzygium (Myrtaceae) for the prevention and treatment of arthritic and autoimmune diseases," Bioactive Food as Dietary Interventions for Arthritis and Related Inflammatory Diseases, Elsevier, Amsterdam, Netherlands, pp. 401-424, 2019.

[90] G. I. M. Mzamane, "Some medicinal, magical and edible plants used among some Bantu Tribes in South Africa," Fort Hare Papers, vol. 1, pp. 29-35, 1945. 